NBER WORKING PAPER SERIES

\title{
COMPARING ECONOMIC AND SOCIAL INTERVENTIONS TO REDUCE INTIMATE PARTNER VIOLENCE: EVIDENCE FROM CENTRAL AND SOUTHERN AFRICA
}

\author{
Radha Iyengar \\ Giulia Ferrari \\ Working Paper 16902 \\ http://www.nber.org/papers/w16902 \\ NATIONAL BUREAU OF ECONOMIC RESEARCH \\ 1050 Massachusetts Avenue \\ Cambridge, MA 02138 \\ March 2011
}

Previously circulated as "Discussion Sessions Coupled with Microfinancing May Enhance the Role of Women in Household Decision-Making in Burundi." The authors are grateful to Jeannie Annan, Oriana Bandiera, Shawn Cole, Erica Field, Michael Kremer, Emily Oster and participants at the NBER Africa Project Conferences and Harvard Development Seminars for helpful comments. The authors also thank Bersebeh Beyene and Gabrielle Cole as well as members of the IRC Burundi staff for assistance in data collection. We thank Prof. Charlotte Watts (London School of Hygiene and Tropical Medicine) for providing us the raw data from the IMAGE study. The authors gratefully acknowledge financial support from the NBER Africa Project and the Centre for Economic Performance. Iyengar also acknowledges financial support from the Robert Wood Johnson Foundation. Any remaining errors are our own. The views expressed herein are those of the authors and do not necessarily reflect the views of the National Bureau of Economic Research.

NBER working papers are circulated for discussion and comment purposes. They have not been peerreviewed or been subject to the review by the NBER Board of Directors that accompanies official NBER publications.

(C) 2011 by Radha Iyengar and Giulia Ferrari. All rights reserved. Short sections of text, not to exceed two paragraphs, may be quoted without explicit permission provided that full credit, including $\mathbb{C}$ notice, is given to the source. 
Comparing Economic and Social Interventions to Reduce Intimate Partner Violence: Evidence from Central and Southern Africa Radha Iyengar and Giulia Ferrari NBER Working Paper No. 16902

March 2011, Revised June 2014

JEL No. D12,G21,I12,J12

\begin{abstract}
The empowerment of women within households remains a major issue around the world including in Africa. We have conducted a study in Burundi coupling discussion sessions with microfinancing to determine if they enhance the role of women in decisions regarding household purchases and the reduction of domestic violence. We compare our findings to that from a published study in South Africa that combined discussion sessions on life skills and health on reduction in domestic violence and decisions on economic issues. Both studies used randomized controlled experiments. Both studies show a trend towards increases in household authority, with the Burundi study showing statistical significance. In South Africa there was a large, albeit short lived decrease in domestic violence. In Burundi there was small reduction but trends suggest a longer duration. The effects on overall empowerment are small. These studies suggest that a more sustained use of discussion sessions may result in longer and more sustained economic and social empowerment. Future research could focus on the longer term effects of the use of discussion sessions and investigate how the observed impacts can be sustained in magnitude and duration.
\end{abstract}

Radha Iyengar

London School of Economics

Department of Economics

Houghton St

London WC2A 2AE

UNITED KINGDOM

riyengar@rwj.harvard.edu

Giulia Ferrari

London School of Economics

G.Ferrari@1se.ac.uk 


\section{INTRODUCTION}

Empowerment of women within households and reduction in domestic violence remains a major issue around the world including Africa. Despite this, there is a lack of broad evidence and little consensus either among scholars or among practitioners as to what programs or policies are effective. In particular, the debate remains as to whether economic conditions, such as wage rates or labor market opportunities, affect bargaining power and reduction in violence on the one hand or whether specific gender-based programs are required. This paper describes an impact evaluation of a financial skills and negotiation training program in conjunction with microfinancing in Burundi compared to data from a previously published study on gender-based training for women receiving microfinancing in South Africa.

The Burundi program coupled discussion groups for both women and men with participation and financing for women in local savings and loan association. The discussion groups focused on financial decision making within households with the aim increasing the role of women in household decision making and in reducing domestic violence towards women. The program was designed to provide women with access to economic resources through village savings and loan associations (VSLA). The International Refugee Committee (IRC) randomly selected half of the members in each of the 25 VSLAs groups to participate in a set of 6 discussion sessions where it shared with women and their spouses progressive attitudes about the role of gender in household decision making regarding finances. The evaluation utilized focus groups to investigate whether the discussion sessions were effective at increasing the role of women in decisions regarding household purchases and concomitantly in reducing violence against women.

In this study we compared the Burundi program to the well-known program in South Africa Microfinance for Gender Equity (IMAGE). The South African study was designed to increase access to resources and reduce violence for poor women (Kim, et al 2009). The program included both microfinancing and a 10-session group course for the women. In South Africa, the study focused on general life skills and specific gender issues like fertility and sexually transmitted diseases. In South Africa the program was purposefully targeted at women and intended specifically to reduce violence in the household.

Both studies show that discussion sessions in conjunction with microcredit participation improves financial decision making authority for women, reduces exposure to violence, reduces acceptance of violence, and increases consumption of household goods relative to luxury goods such as alcohol. The evidence from both studies suggests that discussion groups may be a useful approach for empowering women when applied in combination with the improved economic access provided by microcredit participation. In the following sections we present the program and evaluation designs, the sources of data and the related timeline and outputs. 


\section{BACKGROUND}

Programs to reduce gender-based violence have spanned a range of countries in Southern, Central, and Eastern Africa with varying degrees of success. In part this is because these programs have been largely divorced from theories on underlying causes of intimate partner violence. Theories on the relationship between resources and violence are abundant in several disciplines including psychology, sociology and economics. Despite this there is limited empirical evidence to distinguish between these models.

In psychology, there are a range of theories and explanations for violence. Broadly speaking, there have been two types of theories. ${ }^{1}$ The first characterize violence as due to either a lack of control during escalating arguments. Such violence programs focus on anger management programs and more detailed cognitive behavioural therapy as a means to reduce violence. (Dutton and Corvo, 2006). If increased resources reduce conflict within the household then regardless of who the resources are provided to, violence should reduce. On the other hand, if female resources increase conflict then the chance of escalation to violence increases. An alternative theory is that violence is a strategically chosen systematic means to exercise control. Strategic violence for the purposes of control might therefore increase as women have increased access to resources.

Work by sociologists and criminologist largely focuses on social and contextual causes of violence but parallels closely the psychology theories. In these fields, there are two prominent sets of theories: "exposure" and "backlash". The exposure theory focuses on the amount of time spent together. This is similar to the violence is due to lack of control described in the psychology literature. Programs that increase income-generating activities by women or generally increase separation will reduce violence by reducing the time partners spend together. Similarly, increased unemployment by men may increase violence by increasing the time partners spend together (Laura Dugan, Daniel Nagin and Richard Rosenfeld, 1999). The other theory is that of "male backlash" related to the strategic violence theory cited in psychology. Aizer (2010) gives a detailed description of this literature but the basic concept is that increased financial independence by women increases repression by men in other areas of interaction. As a result, increased access to resources for women will increase violence.

In contrast, work by economists typically focuses on modeling household interactions. While neoclassical models of unitary household decision making (such as Becker, 1965) are still used occasionally data from a wide range of settings have rejected several features of the unitary model. This has led to a now large literature that models household decisions as the result of bargaining among household members (e.g., Browning and Chiappori 1998). These models have helped frame findings from developing countries that show that increases in the female share of household income, interpreted as providing the woman more power within the

\footnotetext{
${ }^{1}$ There is a rich and detailed psychology literature on both the motivation and effects of intimate partner violence, a full review of which is beyond the scope of this paper. For a more detailed treatment, see Johnson and Ferraro, 2000.
} 
household, induce an allocation of resources that better reflects her preferences (Duflo 2003; Rangel 2005). This allocation tends to feature greater investment in education, housing, and nutrition for children (Strauss and Thomas 1995; Duflo 2003). Many now see women's empowerment as key to improving the welfare of women and children. To date, however, there is little evidence that externally induced "empowerment" is effective. While experimental evidence does suggest that legal control of a new asset empowers women (Ashraf, Karlan, and Yin 2006), this empowerment effect is short-lived. Typically these models do not include violence though adaptations by Aizer (2010) and Pollack (2005) present results where the man's utility increasing in violence and the woman's decreasing in violence. In such models, increased resources increase women's bargaining power suggesting that violence should decrease. However, this is only true if the increased resources imply an increased outside opportunity.

Empirical evidence distinguishing the theories largely comes from economists who have employed structural methods or used panel data to overcome the problem posed by endogenous wages. Bowlus and Seitz (2006) use structural methods to estimate a negative impact of female employment on abuse. Tauchen, Witte and Long (1991) and Farmer and Tiefenthaler (1997) utilized panel data on victims of domestic violence to examine the impact of changes in a woman's income over time on violence. In all cases, there is limited ability to distinguish between resources affecting violence and reverse causality of violence affecting resources and unemployment. Recent work by Aizer (2009) uses demand shocks in femaledominant sectors to identify the effect of increased wages on violence. Aizer's findings suggest increase resources reduce violence and are thus inconsistent with the backlash/strategic control models that predict that as women's wages increase, violence against them increases. In addition, Aizer find that violence reduction occurs during non-working hours, inconsistent with the exposure/lack of control models as well. Aizer's work provides important insight into settings where outside options improve and women have substantial economic and social freedom. In many settings across the world and particularly in Sub-Saharan Africa, women have few outside options. Women often have few legal rights and there is extreme social pressure to stay in marriages that are often extremely abusive. There is even more limited evidence on the role of resources and negotiations in these settings. The only existing evidence on the impact of women's economic status on domestic violence comes from an experiment in South Africa and Burundi VSLA interventions described below.

\section{EXPERIMENTAL EVIDENCE FROM SOUTH AFRICA AND BURUNDI}

Among the most prominent of these experiments to reduce intimate partner violence was the program with Microfinance for Gender Equity (IMAGE) in South Africa, a cooperative study between the London School of Hygiene and Tropical Medicine (LSHTM), Wits University in Johannesburg, and the microfinance NGO Small Enterprise Foundation (SEF). When this study was first implemented, SEF had been working in the Limpopo Province of South Africa for nine years. Limpopo is one of the poorer provinces in South Africa, with $50 \%$ of its population earning 800 Rands or less a month in $2001^{1}$. The IMAGE pilot was introduced in the peri-urban 
area around the mining town of Burgersfort, Sekhukhuneland. The researchers from LSHTM and Wits Universities structured a 10-session curriculum on life skills, health and gender training to be administered to the women receiving microloans. The sessions were structured as discussion forums for adult learning facilitated by a group of social workers specially trained for the task. The ten sessions were offered to women fortnightly, at repayment meetings. The training entailed the discussion of gender roles and self-awareness, as well as communication on difficult issues, especially around HIV, and within the household. ${ }^{2}$ The training was bundled into a package that also entailed participation into the pro-poor group-lending program that SEF runs in the province, based on the Grameen model of group lending schemes, where participants form groups of five individuals that are jointly liable for the repayment of their individual loans.

The framework followed by the IMAGE researchers is illustrated schematically in Figure 1. As shown in the diagram, there is a common risk environment that determines a number of structural - in public health terms - and cultural and socio-economic conditions that determine the vulnerability of the women. The aim of the IMAGE program was to break this vicious cycle by breaking the cycle of poverty the women are trapped into and alter the women's perceptions of gender norms, thereby increasing their empowerment not just by giving them access to increased income, but also by altering their attitudes to violence and their decision making skills.

\section{[INSERT FIGURE 1 ABOUT HERE]}

In 2001, the IMAGE study was designed as a pilot study of the introduction of a microfinance and training (mf plus) product in a new market. It was geared towards understanding the intervention's efficacy, in view of possibly expanding operations in the area. To our knowledge it was the first randomized controlled trial of an $\mathrm{mf}$ plus. It compared the full package of microfinance and life skills and gender training versus no program participation. ${ }^{3}$ This is in line with the multifaceted nature of the risk that the study hypothesized the individuals to be faced with, and does not allow us to disentangle the effects of each component' but only to observe their joint effect. ${ }^{4}$

\footnotetext{
2 1Equivalent to 93USD a month at 2001 exchange rates (calculated at September 2001; source: http://www.oanda.com/currency/converter/ )

${ }^{3} 2$ This would ideally also include an intervention with life skills training only, although the difference here is that these types of discussion forums typically do not enjoy the regularity in attendance that microfinance program based sessions typically do. This, as noted above, is possibly one of the reasons why life skill training programs are often coupled to microfinance program.

${ }^{4}$ A subsequent cross-sectional study compared the two initial groups at follow up with a third group of women in similar villages that only had access to microfinance, and found that the latter group tended to fare better on most economic outcomes, while the full intervention group fares comparatively better on all of the other empowerment and violence-reduction outcomes (Kim et al., 2009). Further, the group exposed to full treatment seemed to do better on some longer term economic outcomes, a finding that we corroborate from the Burundi study we present here. Further investigations of these trends may be useful and here we also analyzed the data from Kim et al (2009)
} 
The IMAGE evaluation assigned villages randomly to treatment (microloans plus discussion sessions) and control. The study villages were first assigned to three different groups on the basis of their size and accessibility - large and accessible, two pairs of medium and accessible, and small ad inaccessible - to reflect the typology of villages in the area, because it was hypothesized that villages that were larger and closer to main roads would have a more dynamic market than smaller villages, or villages that were not as close to main roads. Village characteristics were measured during field reconnaissance visits, due to lack of census data on these villages at the time the pilot started.

Randomization happened at the level of the cluster defined by the village pair, and individual villages were randomized either to treatment or to control by means of a lottery. Each of the three clusters contained two villages, and the lottery assigned these randomly to treatment immediately, or to deferred treatment. The women joined in groups of five in each village, generating between a minimum of 9 to a maximum of 30 groups per village.

Within both intervention and control villages, the pool of individuals eligible to join the program was identified by means of a participatory rural appraisal technique, called participatory wealth ranking (PWR), devised by the collaborating NGO, and whose consistency with statistical methods has been tested and discussed elsewhere (Hargreaves et al., 2007). The program was designed to measure the effectiveness of the intervention, and it compared treated individuals in the villages assigned to treatment versus non-treated eligible individuals in control villages; this implies that we would find some statistically significant differences at baseline for sociodemographic characteristics that could bias the estimates, and that we therefore controlled for. Finally, because the level of treatment is the village, we clustered the errors at the village level. Program evaluation happened at two points in time: the baseline survey was collected in 20012002, and the follow up survey in 2003-2004, so that each individual would be interviewed 2 years after their baseline interview. Interviewers received one month of training prior to going to the field.

In contrast to previous efforts to enhance women's empowerment, the program in Burundi did not to focus on women's empowerment explicitly, fearing backlash in the home and community, and increase women's vulnerability to violence in the short-term. Instead, the program approached the issues of empowerment and gender-based violence subtly by encouraging discussion among partners to analyze how men and women relate to one another within the privacy of their homes in negotiating access to and control over household resources. While the courses did not explicitly deal with gender issues, the hypothesis driving the program was that encouraging husbands and wives to discuss household decisions and respect women's opinions may improve women's decision making power in the home. The courses were conceived to help facilitate a household atmosphere where women (and their opinions) would be more valued and violence against them becomes a less acceptable way of solving issues and conflicts. This change in attitudes and respect could reduce vulnerability to violence within the household. 
The Burundi program, run by the IRC, established the pilot VSLA program in the Makamba province of Burundi. The pilot project involved 25 groups across the Makamba Province in Burundi: 7 in Nyanza-Lac, 6 in Kibago, 6 in Kayagoro, and 6 in Mabanda. In addition to implementing the VSLA methodology according to the guidelines and principles developed by CARE International, researchers from London School of Economics (with input from IRC) developed a 6-course discussion group series that addressed household decision-making along gender lines, the respective roles of women and men, and the use of violence against women in the home more broadly. Half of the participants in the VSLAs were invited to attend these discussions with their spouses. IRC staff members from the gender-based violence program were trained to facilitate these discussion groups. The basic logic model is presented below. This impact evaluation is among the few detailed studies IRC has ongoing in post-conflict countries. IRC has partnered with academic evaluators in Liberia, Congo, and Cote d'Ivoire, to assess the net difference its work makes for people and investigate what works best to accomplish IRC objectives. ${ }^{5}$

The Burundi evaluation is relatively unique because it used randomization more narrowly than other evaluation designs that are based on a complete random assignment of units (communities, villages, individuals) into treatment and control. Such broad randomization, although very valuable for testing overall effectiveness does not provide insights into what parts of a program work and how existing programs may be specifically enhanced. In Burundi, the VSLAs were already formed at the time the evaluation began, thereby limiting the random assignment to units into which individuals had already self-selected. Thus, although this evaluation cannot assess the effectiveness of the VSLA program overall - which would require a control group that does not receive VSLA - it can assess the degree to which an important additional variation of the program design is more or less effective at influencing women's empowerment, defined here as their ability to not only access economic resources but also participate in controlling them.

The cluster unit of randomization was the VSLA but randomization occurred at the individual level, with half of each VSLA's members selected randomly into the treatment - i.e. the discussion groups - through a lottery, held in each VSLA. ${ }^{6}$ Slips were drawn from a hat, and those with "winning" slips were the ones who entered the discussion groups with spouses.

\footnotetext{
${ }^{5}$ This project was approved by Harvard University Human Subjects (Application Number: F15660-101)

${ }^{6}$ The VSLA groups initially formed through members of the community designated as community based facilitators (CBF).The IRC identified CBFs during community mobilization on the VSLA approach. The IRC was able to reach four communes and eight zones. After having explained the VSLA approach and the role of CBFs, community members elected two or three people. In each commune, the IRC invited 4 CBFs (for a total of $16 \mathrm{CBFs}$ ) to a meeting where a transparent selection process was conducted to identify the $8 \mathrm{CBFs}$. The IRC chose two individuals that fulfilled all or the majority of the criteria in each commune. At the end of the process, the IRC had retained $8 \mathrm{CBFs}$, four women and four men as facilitators. Each commune had one female and one male facilitator. The CBFs were responsible for training groups in the VSLA methodology. Appendix Table 1 lists the CBF identifiers, sex, and the gender composition of each group.
} 
Those selected were invited to attend a 6 session course on household decision-making with their spouses. ${ }^{7}$

The program was evaluated at different points in time, and both quantitative and qualitative data were analyzed statistically, in order to fully capture the complexity of the programmatic impact. After the initial formation of groups through the community-based facilitators the IRC conducted a baseline survey of all participants to determine attitudes and assess comparability of treatment (discussion group attendees) and control groups. During the course of the discussion groups, IRC designed monitoring tools were used to test the comprehension and retention of discussion group material. These tools can also used to improve the quality of how the discussion groups are designed and facilitated along the way and during the 2nd phase of implementation. After the conclusion of the discussion groups, the IRC conducted a second survey to determine direct immediate-effect of discussion groups on attitudes. At this stage, the IRC also conducted four focus groups, with both treated and non-treated men and women, to contextualize and enrich the quantitative findings from the post-discussion focus group survey. After the VSLA groups had completed their one-year cycle, and savings plus interest had been distributed to all participants, the IRC conducted a final survey of the short-run effects of VSLA participation and attendance in facilitated discussion groups on reported outcomes. In theory, participation by both men and women can also open up opportunities for dialogue over economic decisions from more equalized positions of power, which is often a critical barrier to economic self-reliance among women. The discussion sessions were conceived to improve attitudes towards women's empowerment, thereby decreasing their vulnerability to violence in the home. We formulated and tested four hypotheses to investigate whether and how women's empowerment was increased and their vulnerability reduced as a consequence of the intervention.

\subsection{Sampling and Design}

\subsubsection{Burundi}

The sample of treatment and control participants was drawn from the VSLA groups initially formed through members of the community designated as community based facilitators (CBF).In order to determine the sample size necessary to detect a significant change in the outcome measures, we conducted a power analysis of a one tailed test of Treatment = Control against the two-sided alternative Treatment $\neq$ Control. To conduct a power analysis to determine feasibility, we used previous related work by Kim, et al (2007). Kim et al provided microfinance and sexual health and empowerment counseling to women in South Africa, and found that average effect sizes among treatment group women revealed a reduction of almost half relative to their control group counterparts. With such a large effect, the pilot study sample of 500 would be sufficient to detect statistically significant change.

\footnotetext{
${ }^{7}$ All participants were informed that due to space constraints, only half of the members would be able to attend. In each discussion group, individuals drew numbers from a bag or hat. Those who drew a "winning" number were invited to attend the groups. Others were informed that they would not participate this time but would hopefully be able to participate in the next round. The lottery was conducted this way due to concerns that choosing half of the discussion groups would result in insufficient statistical power to detect an effect.
} 
To determine if such a distribution was applicable to the Burundi population we compared the results from the baseline survey to the South African sample. The baseline survey used the Hurt, Insult, Threat, Scream (HITS) screening tool. ${ }^{8}$ This tool was designed as a "paper-andpencil" instrument for identifying both physical and verbal abuse. It includes four items: physical abuse (such as hitting or punching), insults, threats and screaming. The four items are scored on a Likert 5-point scale. ${ }^{9}$

Baseline results indicate that the distribution of violence among respondents in Burundi is similar to that of respondents in the South African sample analyzed by Kim et al. Applying the same distribution (mean and standard deviation) of the population in Burundi would imply that the minimum effect size the current pilot could significantly detect is a 27 percent change in outcome values. This is significantly smaller than the economic well-being and attitude effects detected in Kim et al (2009). ${ }^{10}$

To increase power for analysis, the sample was randomly drawn from each of the 25 groups so that the probability of being chosen for any respondent was 50 percent conditional on being in their VSLA group. Because of a small number of absences, the overall probability of any given VSLA member being chosen to participate in the discussion groups was 48 percent. Absences were random and so this slight divergence does not significantly affect the comparability of the control and treatment groups.

\subsubsection{South Africa}

For the study of the IMAGE program, no prior estimates of impact for similar studies existed for all outcomes(Hargreaves et al., 03PRT/24), hence the protocol for the study published expected outcomes and interval estimates for such outcomes, discussing the sensitivity of results to changes in key statistical parameters. In particular, because the power for the estimation of impact in randomized trials at the village level is influenced by the number of villages included in the study, the number of individuals in each village, and the intra-class correlation coefficient within each village, the IMAGE protocol presented expected estimates and relative precision

\footnotetext{
${ }^{8}$ Sherin, Kevin, et al. "HITS: A Short Domestic Violence Screening Tool for Use in Family Practice Settings" Fam Med 1998;30(7):508-12.)HITS is used globally now in China, Saudi Arabia, the Middle East, Africa, Europe, and South and North America. It has been validated for women in Spanish, and partner violence with males. In the US, the HITS tool is used or has been recommended by Kaiser Permanente Group of Northern California, The New Jersey Hospital Association, the Alaska Department of Health and Human Services, Parkland Hospital in Dallas, the Department of OB GYN at USF in Tampa, the CDC, and others. It has been translated into multiple languages including Mandarin Chinese and Arabic.

9 It has been validated against the CTS in a study of 160 female patients in an urban/suburban family practice setting and 99 self-identified abused women. The HITS scores were strongly correlated with the CTS, with sensitivity and specificity of $96 \%$ and $91 \%$, respectively. Positive predictive and negative predictive values in the family practice setting were $87 \%$ and $97 \%$, respectively.

${ }^{10}$ We show that the randomization into the different treatment groups was successful, and that participants do not differ significantly along any identifiable socio-economic dimension. This is an important step in the evaluation design, because it tells us whether the groups generated via the randomization process are indeed good counterfactuals for one another. As the analyses below illustrate, the groups do not differ in any statistically significant way on average and thus do constitute good counterfactuals for one another. In turn, this allows us to attribute any statistically significant difference in the outcomes to the intervention.
} 
taking these elements into account. ${ }^{11}$ However because virtually no data was available on either the intra-class correlation coefficient, nor on various outcomes variables, the protocol reported a range of such estimates, for different values of both baseline prevalence rates and intra-class correlation coefficients for the key outcomes it focused on. ${ }^{12}$

\subsection{Distinguishing Between Theories}

The evaluation design allows distinguishing the effect of increased resources in addition to discussion sessions. Broadly the studies test whether increased access to resources results in increased control of resources and the extent to which improved information on the benefits of cooperative household decision making relative to sole-male, sometime violence decision making reduced violence. In both studies, the underlying hypothesis is that the program acts by both improving the woman's economic status and her ability to negotiate her role within the household. In turn, this should imply that the resources she brings into the household remain under her control to a greater extent because she has learned to better negotiate her role; and her demands for increased autonomy are less likely to be perceived as threatening by the man, because the woman is bringing in resources of her own, and therefore may be seen as more of an equal by her partner.

Compared to a situation where the women are do receive microfinancing and participate in discussion sessions, the joint administration of these two services should support the woman in improving her status in the household in a non-threatening, and rather constructive manner, so that she may play a more autonomous and constructive role in household decision making, and thereby reduce her exposure to violence.

If increased resources reduce conflict in the household then microfinance programs alone may be sufficient to reduce violence. However, if who receives resources matter, this may be due to either the economic bargaining model by economist or the backlash/strategic violence theory by sociologists and psychologists. If increased resources to women reduce violence, this is supportive of the bargaining model. However, changes in resource levels should only salient if women have access and decision making power over the use of these resources. Thus the question also arises about whether if changes in resource control are required, this may better accomplished in single sex or mixed sex interventions.

The two investigations in South Africa and Burundi explore different facets of women's empowerment and reduction in domestic violence in sub-Saharan Africa in ways that reflect the intrinsic differences in study design, as well as the different socio-economic contexts. The IMAGE study mostly focused on the dimension empowerment related to autonomy - i.e. the ability of the individual to think and for themselves, independently of what others around them

\footnotetext{
${ }^{11}$ Except for HIV data.

${ }^{12}$ We report the baseline values for a number of relevant socio economic dimensions and demographic characteristics, which show the extent to which the randomization was successful. Women in the two groups are not statistically different on a number of accounts that will be shown below, and belong to the same socioeconomic milieu according to the participatory wealth ranking exercise carried out by the microfinance NGO to identify the group of poorest individuals in the village (Hargreaves et al., 2007; Simanowitz and Nkuna, 1998).
} 
say. Thus, it encouraged the women to think for themselves, and see themselves as more selfinterested individuals compared with the role of women who were not in the program. The Burundi VSLA intervention, in contrast, focused more on the aspect of empowerment that has to do with positive relations with others - i.e. meaningful connections with significant others that are mutually enriching and constructive. These intrinsic difference explains the exclusive focus on women we find in IMAGE, and the inclusion of clients both genders in the Burundi VSLA, respectively. Further, both programs were designed to respond to the local environment they were introduced in, to enhance their respective salience in relation to the local context and, by so doing enhancing their chance of successfully achieving their stated targets. Thus, IMAGE was geared toward South African women in peri-urban areas, who have a tradition of joining women's groups, both for economic purposes - as the presence of numerous women's stokvels-locally initiated rotating savings associations indicated, and for political and social purposes (Bozzoli, 1990). The program in Burundi, owed its structure instead to the fact that IRC preferred to entertain a dialogue with both genders, in an effort to offset previous failed attempts that had exclusively focused on women, and in order to reduce the likelihood of rejection on the part of the population of an intervention that only focused on women, given the very conservative nature of the local culture in Burundi. 
Summary of Comparative Measures

\begin{tabular}{|c|c|c|}
\hline Question & Burundi VSLA & South Africa IMAGE \\
\hline Household Roster (relation, age) & Y & Y \\
\hline Education & Y & Y \\
\hline Displacement & Y & $\mathrm{N} / \mathrm{A}$ \\
\hline Assets & Land Ownership & $\begin{array}{c}\text { LO }+ \text { index of hh } \\
\text { durables }+ \text { heads of } \\
\text { cattle } \& \text { other } \\
\text { domestic animals }\end{array}$ \\
\hline Consumption & Y (past 2 weeks) & $\mathrm{N}$ \\
\hline Who decides on a variety of issues & Y & $\mathrm{Y}$ \\
\hline How disputes get resolved & Y & $\mathrm{N}$ \\
\hline Attitudes towards women's roles and rights & Y & Roles Only \\
\hline Controlling Behavior & $\mathrm{N}$ & $\mathrm{Y}$ \\
\hline Violence Levels & $\begin{array}{c}\text { HITS Tool (past } 2 \\
\text { weeks) }\end{array}$ & WHO Tool (past 12m) \\
\hline Response to Violence & $\mathrm{N}$ & $\mathrm{Y}$ \\
\hline Knowledge of \& Communication on HIV & N/A & $\mathrm{Y}$ \\
\hline Networks \& Community Participation & $\mathrm{N}$ & $\mathrm{Y}$ \\
\hline
\end{tabular}

\subsection{Quantitative Data}

\section{METHODS}

\subsubsection{Burundi}

The evaluation relies on 4 sources of data: 1) a baseline survey conducted in January, 2008; 2) a post-discussion group survey conducted in July, 2008; 3) qualitative monitoring to complement the discussion group findings in January 2009; and 4) a final survey conducted in April 2009. These, together with the methods used for data analysis, are briefly described . 
The Survey Instrument

The three waves of survey collected data on household consumption, decision making and conflict resolution, gender roles, attitudes toward violence, exposure to violence, women's rights. The first wave of the survey also included a household roster; while the second also included sections on asset ownership and income, VSLA loans and savings, and wealth and wellbeing. The measure of exposure to violence used in this survey is the Hurt Insult Threaten Scream (HITS) instrument (Sherin et al., 1998). The HITS was chosen due to its proven applicability in a variety of settings, and because it allows for a rapid appraisal of past experiences of violence. Its measurement regards the two weeks prior to the interview. The surveys were conducted by 12 interviewers, 4 of which were males. Each interview lasted approximately 30 minutes

\section{Analysis}

The data was collected in Excel spreadsheets and imported into Stata, a statistical package widely used for econometric analysis. We performed regression analysis on the data, using a 'difference in differences' approach. This method allowed us to compare the magnitude and statistical significance of the relative change in the outcomes of interest experienced by the relevant groups as a result of the treatment, compared to the initial situation. The rigorous randomization design allowed us to attribute the observed changes to the intervention.

\subsubsection{South Africa}

The Survey Instrument

The two waves of the IMAGE panel contained data on socio-demographics, group membership, community participation, household dynamics, economic well-being and shortages, HIVIAIDS awareness and communication, societal norms on gender roles, decision making in the household, intimate partner violence including controlling behavior, responses on experiences of abuse, and questions on loan performance for microfinance clients. Importantly, the tool that measures exposure to violence in the IMAGE study - based on the WHO indicators of domestic violence as found in the WHO multi-country study (WHO, 2005) - measured incidence over a period of 12 months prior to the interview. This implies that comparisons between the HITS results from the Burundi intervention and the tool used for IMAGE are not directly comparable. The measures of exposure to violence used in the two evaluations differ in terms of the time span they cover.

The women were also administered a household questionnaire that included a household roster, questions on the type of the two most significant sources of income, characteristics of the dwelling, household assets, credits and savings, perception of own wealth, and food security. Questionnaires were in total about 25 pages long, and took 40 minutes to one hour to administer. Interviewers were all females, and during the month long training prior to the first wave of survey data collection they learned interviewing techniques for sensitive issues, and studied the questionnaire in depth. 
Analysis

The data was entered in Access databases, and transferred into Stata. We used the 'differencein-differences' approach in an OLS model to measure impact. We clustered the errors at the village level, as this was the level at which treatment was administered, and control for village pair effect, as these are identify geographical characteristics of relevance, as well as for a number of socio-demographic variables to correct for baseline imbalances.

\subsection{Qualitative Data}

There were important differences in the way the qualitative data were collected in South Africa vs. Burundi.

The qualitative data from South Africa used in this study focused on the understanding of the women's conception of subjective well-being (SWB) and was used to formulate initial hypotheses as to what aspects of SWB the objective measures of empowerment may relate to exposure to violence. For the Burundi project the qualitative data were the transcripts of the discussion sessions. The data from Burundi was collected in a manner that could be analyzed statistically by the text analysis program Alceste.

\subsubsection{Burundi}

The Focus Group Data Collection

Perceptions and customs around decision making within households including on daily and major household purchases, family planning issues and women's ability to negotiate sex, domestic violence and the recent conflict between different ethnic groups were investigated in focus group discussions. We used verbal descriptions to obtain answers to questions.

We then analyzed the transcripts from focus group sessions to enrich and contextualize the interpretation of the quantitative data. In line with the underlying evaluation design, focus group participants were divided into focus group according to their treatment status, and further separated by gender, so that a total of four focus groups were run: one with treated women and one with non-treated women; one with treated men and one with non-treated men. One moderator supported by an interpreter conducted each focus group. A female moderator and interpreter conducted the focus groups with the women, and a male moderator and interpreter those with men, because it was thought this would favor a greater degree of understanding and trust during the sessions. At times, especially for the most delicate parts of the discussion, moderators and interpreters explicitly appealed to this form of trust and understanding, to reassure participants that their thoughts would be comprehended, valued, and respected. ${ }^{13}$

The focus groups all had the same structure, and therefore produce information that may be compared across the different groups. The sessions open with the moderator and interpreter

\footnotetext{
${ }^{13}$ In the following excerpt the female facilitator introduces the part of the discussion on violence to the women in the discussion group Let us now talk about violence. I would like to remind you that you are free to talk according to your understanding, and whatever you say will be confidential, you know we are almost the same age, so, feel free to express yourselves. Tell me, when a man is angry, what kind of reactions can he have?"
} 
briefly explaining the purpose of the focus group, introducing themselves, and requesting an informed oral consent of participants. The focus groups interactions were mainly devoted to obtaining answers for eight key questions, some of which were further articulated as subquestions or themes: the market day, joint decision making, women and their ability to manage money, the ethnic conflict and marital relationships, family planning, and conflict and violence within the household.

Analysis

The verbal material from the focus groups was analyzed with the aid of Alcesté, a software suite for the analysis of the content of textual data. The software applies a statistical technique called correspondence analysis to identify themes (technically called classes) in the text; this is done by computing the relative frequency and co-occurrence of different parts of speech in the text. By identifying those elements in the text's vocabulary that tend to occur together, the software defines the key themes woven in the text itself. This technique is useful in the analysis of text that reports responses to open questions, as it allows us to characterize the worldviews of respondents associated with the prompts they were given. This feature makes Alcesté particularly apt for the analysis of the material from the focus groups conducted in Burundi, where the moderators only gave hints to introduce the themes they wanted to discuss, and let participants express their own personal views in their own manner on these themes. The software identified seven separate themes that we discuss below in conjunction with the results from the quantitative econometric analysis of the survey data to more fully capture the impact of the intervention.

\subsection{Comparison of Results}

The results are presented separately for our own data from Burundi and our analysis of the Kim et al data from South Africa. We provide the results in the immediate context of the hypotheses outlined above. The results are described around the three broad themes of financial decision making, attitudes to violence, and violence outcomes, integrating both quantitative and qualitative findings for Burundi. This integration allows us to provide a rigorous discussion of the hypotheses in light of results while contextualizing them clearly into the areas of relevance for policy making. Only quantitative analysis is provided for South Africa, as Kim et al are currently conducting qualitative analyses of their data.

The tools used in the two interventions to measure experience of domestic violence differ somewhat, the Burundi intervention relying on the HITS measure (Sherin et al., 1998), and the IMAGE intervention relying on the WHO methodology found in the WHO multi-country study on violence against women (Garcia-Moreno et al., 2005). However slightly different, both these measures capture a measure of physical assault - push, and hit with a fist or object in the case of IMAGE; and physically hurt you, in the case of the VSLA intervention in Burundi - as well as a measure of insult, though the IMAGE instrument only gages whether insults are administered in public, and is therefore likely to capture less instances. The two measures differ in that the HITS measure also captures instances of threat and cases when the woman has been screamed at, and hence in general focuses on aggressive behavior of the man toward the woman broadly understood. The IMAGE tool looks explicitly as sexual violence, investigating 
whether the woman has been forced to have sex and/or has had sex for fear of the consequences, had she refused to, and also at controlling behavior more generally. In both cases, the choice of questions is related to the context where the interventions were introduced, which in turn, as we have seen, determined the nature of the interventions themselves. In the case of IMAGE, the choice of asking explicit questions about sexual violence may be connected both to the widespread incidence of sexual violence itself, and by the fact that in South Africa this is an issue that is openly discussed in the media, and by policy makers. In contrast the choice of the HITS tool - whose efficacy in detecting instances of domestic abuse is documented (Sherin et al., 1998) - has rather to do with the overarching spirit of the intervention, and the choice not to focus explicitly on domestic violence in order not to alienate men and the general population in the communities where it was introduced.

\section{RESULTS}

We report on results from our analyses of the effects of programs that couple microfinancing with discussion sessions in Burundi and South Africa in the areas of decision making, attitudes to traditional norms and violence against women, and reported exposure to violence, both in the form of controlling behavior on the part of men and of more direct forms of violence. The results are shown so as to assess the degree to which the programs have met the targets they had originally defined. For each program, we first provide an overview of results to convey the overall impact of the program; we then evaluate the success of the randomization, in order to justify the econometric models, and then describe the results in relation to the hypotheses we formulated for the two programs. We focus on the specific indicators related to these hypotheses for each program and develop a comparative perspective. We discuss the common and discordant features of the results from the two programs.

\subsection{Burundi}

The VSLA microfinancing program coupled with the discussion sessions in Burundi was targeted at reducing male control over all household decision-making. Included in this, was the goal of changed attitudes towards household violence. If successful in execution, both men and women who participated in the discussion sessions will have developed a more nuanced understanding of domestic violence without an explicit discussion or consideration of violence. In particular, women who participated in the discussion sessions would be able to describe the elements that constitute the 'cultural risk environment' for domestic violence. 'Cultural risk environment' the set of criteria that identify an acceptable behavior for the woman in the household and that at the same time underscore her lesser stand in the negotiation of roles.

In testing the impact of the Burundi program, we find that participation in the discussion groups is associated with increased decision making for women. In particular, $26 \%$ more women in the discussion groups report an increase in spending on their own earnings. There is no substantial change in decisions on how men's income is spent. In addition, women report increased decision making authority over major household purchases also increases by nearly $14 \%$. This change in decision making directly impacts household consumption with women reporting and 
more than $11 \%$ increase in household consumption. Attitudes towards violence changed by $9 \%$., with men reporting more often that violence was unacceptable, in particular, when the wife is perceived as neglecting the children and when the wife refuses sex. However, these changes in attitude are not reflected in substantial changes to violence exposure. The program appears to reduce violence by less than 1 percent.

\subsubsection{Verifying Randomization}

Before considering the initial reported attitudes of VSLA participants on gender issues, we asked respondents detailed information about their household, including information about displacement, education, and wealth. This information is important from a methodological standpoint because it provides important information to test that discussion session participating and control communities are similar across a range of background variables that might shape the outcomes of interest or impact the efficacy of the program. In addition, the data offers a detailed picture of the VSLA participants many of whom are recent returnees to post ethnicconflict Burundi.

The individuals who selected into the VSLA program were not necessarily representative of all Burundians About two-thirds of participants and thus roughly as many respondents are female (69 percent). The average age of participants is 37.9 , with the youngest participants at age 15 and the oldest at age 80.On average, respondents had 4 children living at home. The maximum number of children living at home is 12.Just short of two-thirds (61 percent) had young children (under 5 ) in the household. Only 2.2 percent of respondents reported never being displaced due to the ethnic conflict. More than half of respondents were displaced from their homes but remained within Burundi while 41 percent of respondents reported having to leave their homes and Burundi due to the ethnic conflict. A majority of participants own some land (72 percent). Among land owners, the average number of hectares owned by the household is 4.5 hectares. Approximately 61 percent of respondents had attended some primary school. Only 16 percent of respondents had attended secondary school.

An important component in ascertaining the validity of an experiment is comparing the outcome variables of interest in the control and treatment groups to ensure that there are no systematic baseline differences. If randomization is successful then on average there should be no statistically detectable difference between the control and treatment groups for baseline variables. Confirming this, we found that almost no outcome variable recorded a statistically significant baseline difference between average values recorded in the participants' and non participants' groups respectively. ${ }^{14}$

\section{[INSERT TABLE 1 ABOUT HERE ]}

The only statistical difference in characteristics prior to the discussion sessions was whether the husband that decides how the money his wife earns is to be spent. The discussion session

\footnotetext{
${ }^{14}$ The comparison of pre-treatment variables are shown in appendix table 1
} 
participants reported an approximately $10 \%$ rate (that is for discussion session participants, more husbands decided how the money the wife earned is to be spent). This difference in one pre-treatment outcome is not of concern given the large number of outcome variables tested. Statistically, there is a $5 \%$ chance that an outcome would appear significantly different, consistent with our baseline results.

To ensure the groups appear similar on observable characteristics we also compared sociodemographic variables. The two groups are also similar along socio-demographic lines, with no variable recording a statistically significant difference between the two groups.

\section{[INSERT TABLE 2 ABOUT HERE ]}

In both groups, approximately $60 \%$ of respondents are females. The two groups also do not differ significantly in terms of amount of land owned: both spouse and respondent own on average 2 half hectares of land, and the majority of spouses do not own land jointly.

\subsubsection{Decision Making Authority}

The first objective of the Burundi program was to improve women's participation in decision making. Women's participation in decision making in the household is generally considered as an important step in their emancipation. If she learns to take part in the management of household matters, and if her husband learns that it is useful to listen to her, this is interpreted to indicate a greater appreciation of the woman's input in the household and, in turn, to lead to a reduced likelihood that she is subject to violence. The intervention aimed to improve decision making dynamics in this direction, encouraging both men and women to take increasingly more decisions jointly. We identified several areas which may be critical to women's empowerment: income/asset-related decision making authority, fertility decision making authority, safety, and political rights. ${ }^{10}$

Based on this objective, hypothesis $\mathrm{B}-\mathrm{H} 1$ was that female members of discussion sessions are more likely to be involved in increasing areas of household decision making. Men who participate in the discussion sessions will be more likely than those that do not to believe that women are capable of making decisions in a broader set of areas. Related to this, hypothesis B-H2 was that members of discussion sessions would become more likely to apply negotiation skills during conflict to reduce the risk of arguments escalating to violence

Our results show a statistically significant impact on three of the eight decision making (DM): the husband's role in deciding how the wife's money is spent; husbands deciding unilaterally on large purchases for the household; and husbands deciding unilaterally on how many children to have. In addition, all three indicators show a similar trend, with women reporting having become more able to co-operate. In all three cases, the percentage increase in co-operative behavior among women with respect to the baseline group is 100- fold the increase reported by men in absolute value.

[INSERT TABLE 3 ABOUT HERE ] [INSERT TABLE 4 ABOUT HERE ] 
Tables 3 and 4 report full results for the battery of decision making indicators at baseline and follow-up, Table 4 also reports the percent change in each indicator, relative to the baseline levels. The results suggest that joint decision making on large purchases improves markedly in the group of treated individuals-with an increase in about 15 percent for women relative to baseline decision making authority.. This same trend is observed for decisions on when to visit one's own or one's spouse's family; further, the management of disagreements in these two areas also shows similar patterns, although these results are not statically significant. The results in Table 4 also suggest that negotiation skills targeted as nonviolent resolution of disagreements improve for women in the intervention group. Women are 4 percent more likely to discuss with their husbands when they disagree with both large and daily purchases. $A$ similar trend in negotiation abilities is observed for resolving disagreements in relation to visits to either their own or their spouse's family.

Men in the treatment group report a very small reduction in their ability to negotiate. Although this effect is small in magnitude (less than $1 \%$ ) it appears consistent across various indicators and may be due to heightened awareness of what negotiation entails. The results are most pronounced on decision making on sex, and alcohol and cigarette purchases which are also the outcomes which had the lowest levels of co-operation as well as the areas with the largest influence of men in decision making.

Figure 2 shows the change in whether the respondent's partner decides how to spend respondent's money: female VSLA members who were members of discussion groups reported a $26 \%$ increase in level of empowerment when compared to female VSLA members in the control group at baseline.

[INSERT FIGURE 2 ABOUT HERE ]

Men who participated in the discussion sessions, however, reported a greater degree of control of household money when compared to female participants at baseline, i.e. a lower tendency to cooperate. Though significant at the 95\% level, this decrease in cooperation is 100 times smaller than the increase reported by the women $(-0.27 \%$ on females in the control group at baseline; and $-0.26 \%$ when compared to males in the control group at baseline)

Females who participated in the discussion groups co-operate on major purchases on average $14.26 \%$ more than the women at baseline $(p<0.05)$, reporting an average of 2.347. Men showed a decrease, instead, of 0.14 percentage points in their ability to share decision making on the initial 2.054 average recorded by women in the control group at baseline.

\section{[INSERT FIGURE 3 ABOUT HERE ]}

Females who had participated in the discussion sessions recorded an increase of 0.36 points over females clients in control groups at baseline regarding the decision of how many children to have, recording a $14.12 \%$ increase from $2.542(p<0.05)$. Men reported a decrease of 0.14 percentage points on the initial value reported by women in the control group.

[INSERT FIGURE 4 ABOUT HERE ] 
When considering the full range of the decision making indicators, even those that did not change significantly showed trends similar to the ones illustrated above. In general, the women report an increase in joint decision, while men report a very small (often 100-fold smaller) increase in their own role in household decision making.

This is consistent with the evidence from the qualitative analysis. Two themes emerged in the focus groups related to the economic sphere of access to and management of resources. One theme specifically describes the role of the woman in the management of the household. Typically the activities included were cleaning, making the bed, fetching water and wood, and preparing meals. The role of women in this area was most often associated with her responsibility or duty. The related theme for men contains a very rich description of all activities revolving around the market, and is associated explicitly with men in their role as fathers. This is specifically in relation to the key role they seem to play in providing for their children's school purchases. The sentences characteristic of this theme seem to report the husband is in a dominant position, i.e. as the one who has ultimately privilege to make decisions that revolve around the acquisition of resources in the market, possibly because of his more direct access to money. The focus on woman's duties in the household and her role in its management is associated to the discussion on the division of labor, and was largely concentrated among participants in the discussion sessions. In contrast, the discussion on men's privileged access to the market was prevalent with both men and women who were not participants. This is consistent with some initial effect of the treatment in fostering a more diverse set of perceptions and ideas around the role of men and the household's access to the market among treated individuals. This interpretation is supported by the quantitative results, where a greater degree of joint decision making is reported by both males and females, as opposed to the control groups.

\subsubsection{Attitudes towards Gender Norms and Violence}

A second objective of the Burundi program was to affect attitudes towards domestic violence by challenging traditional views of women. The nature of the challenge was in the economic and decision making sphere but theory suggests that increased decision making authority may enhance perceptions of capability and reduce tolerance and acceptance of violence. The program aimed to improve attitudes in this direction, by encouraging both men and women to consider why conflicts arise and why such resolutions are achieved via violence rather than negotiation. We identified several areas in which violence might be more or less tolerated: mobility, fertility, household behavior and general social/political rights. ${ }^{10}$ Based on this objective, hypothesis $\mathrm{B}-\mathrm{H} 3$ stated that members of the discussion groups would be more likely to think that abuse is never justified.

\section{[INSERT TABLE 5 ABOUT HERE ]}

In general, the program has a positive and statistically significant impact in the reduction of the tolerance of violence in 2 out of the 6 areas measured: neglecting children and refusing to have sex. The impact is stronger than the time trend observed in the control group in the case of kids' 
neglect, and approximately the same when it comes to the refusal to have sex, though the estimate for the control group is more precise than that for discussion session participants. Moreover, the acceptance of wife beating in cases of kids neglect records an increase in rejection of abuse among discussion session participating women equal to 0.137 when compared to baseline females (23\% increase), versus a negligible decrease in the rejection of violence on the part of discussion session participating men $(-0.23 \%)$, also significant at the $90 \%$ level.

\section{[INSERT FIGURE 5 ABOUT HERE ]}

Participants in discussion sessions are less likely to accept violence for indiscriminate reasons and, in particular, if women go out without saying, argue with their husband, burn food, or say something annoying. Female participants in the discussion sessions are less likely to accept violence against women if they say something annoying or for indiscriminate reasons. Unlike for the cases of neglect of kids and refusal to have sex, the change in these other dimensions is however not statistically significant with respect to levels of acceptance recorded by females at baseline for discussion sessions participants.

The control group recorded statistically significant reductions in the tolerance of violence if the wife goes out without letting her husband know, argues with him, neglects the kids, refuses sex or burns food. In all these cases, trends are identical in both groups and for both genders across groups, with a change of approximately the same order of magnitude for women in the intervention and control groups in relation to arguments.

\section{[INSERT FIGURE 6 ABOUT HERE ]}

Moreover, the control group recorded a statistically significant opposite shift in views between males and females: female clients see it as less acceptable that wives be beaten, while men see it as more acceptable. The discussion session participants recorded a similar trend; in both cases, the absolute difference in change is very large (about 100-fold).

\subsubsection{Exposure to Violence}

The ultimate objective of the program was to reduce women's exposure to violence. Rather than approach the norms that affect violence directly, the program in Burundi was based on the theory that improving women's authority over household decisions could challenge the norms that enable violence, thus reducing violence. Based on this theory, B-H4 was that the program reduces the prevalence of domestic violence.

\section{[INSERT TABLE 6 ABOUT HERE ]}

Table 6 presents the impact of the program on reported violence. It appears that females that did not participate in the discussion sessions reported a reduction in the levels of violence in all areas except for the experience of threats. Males who did not participate in the discussion sessions reported an increase in the level of violence imposed on their partners with respect to 
the levels control women reported at baseline, and virtually unchanged from their own report at baseline (conditional average was 1.20 at baseline and is 1.19 at follow up).

Females in the control group reported a statistically significant reduction in the experience of violence at the end of the savings cycle, i.e. when they receive their total savings back, suggesting that the actual access to the savings makes a difference. However, males in this group reported increasing levels of violence in time, and especially once they receive their savings, suggesting that increased access to material resources may induce men to inflict more violence.

Across individuals in the discussion sessions, there is an overall reduction in violence for women. Similarly, men kept reporting higher levels of violence, just as their non-participating counterparts however, the increase is much lower among those in the discussion session than the levels reported by men in the control group. Thus while there may have been a secular trend of violence increasing (perhaps due to other environmental factors), the effect of this increase is subdued among discussion session participants.

Female participants exhibit a similar reduction in the exposure to violence both immediately after the discussion sessions and after receiving their savings. Treated men, like their untreated counterparts, still report stepping up the violence; in this case, however, the increase is much lower and no longer statistically significant. This seems to suggest that while increased access to resources does encourage violence among men, partaking in activities designed to increase their awareness of the importance of negotiation encourages them to resort to violence less frequently than they would otherwise do.

It is critical to note that while Table 6 shows an overall reduced exposure to violence for women in both the intervention and control group, the self-reports may be affected directly by the program. Evidence from Jewkes (1999) shows evidence that women tend to report lower reductions in experienced violence after increased awareness about domestic violence because they are more likely to categorize events as violence relative to their less-aware counterparts. This has been consistently documented over a range of other studies. Men in the control group report increases in violence across the board, significant in all cases except for threatening behavior. Men in the intervention group instead report a more mixed picture, though the changes they report are never statistically significant. In the focus groups men show a finer understanding of the issues around domestic violence; hence, these mixed results may be interpreted as further corroborating the hypothesis that they have developed a clearer understanding of domestic violence. The reported increase may indicate an ability to distinguish improvements in one area from a worsening situation in another.

The analysis of focus group data revealed two themes of discussion related to household violence. The first may be labeled 'modes of violence', as it contains words that refer to the type of violence inflicted on the women. This is mostly reported to be of a physical nature, with effects both psychological and physical on the victim. The main violent acts are beating, insulting, threatening in order of importance. An important form of physical violence that differs from other areas is burning and scorching which both men and women report. This seems to be 
consistent with conflict related dynamics previously identified in the academic literature. In general, the verbs characterizing this theme are verbs of active aggression: beat, burn, hurt. The preposition 'against' is also typical of this theme, further indicating an antagonistic interaction. The juxtaposition of the language of 'psychological' versus 'physical', suggests that violence is not only perceived as physical and there is a sense of what is cause of psychological violence. ${ }^{15}$ Words that refer to feelings associated to this theme are 'anger' or 'mood' in relation to the man and 'frustration' and 'abused' associated to the woman. ${ }^{16}$

Though the focus group data illustrated an enhanced ability to identify and categorize antagonistic physical abuse, it is particularly associated to the focus group run with men that had participated in the program. This is consistent with a greater awareness of domestic violence, and in particular the ability to recognize it and describe its different facets, as well as the implications it has for the victims. This, coupled with lower - though small in magnitude reported threatening and insulting behavior in this group, suggests the participant group may have had some initial impact on the men's perception of what is acceptable and hence on their behavior.

A second issue identified in the focus group is the acceptability of some forms of physical violence. Thus violence associated with aggressive behavior on the part of the man, and in particular violence initiated because of changes in his mood is considered distinct relative to violence instigated by the wife's behavior or the general social conditions. The nature of violence is most often categorized as reasonable versus unreasonable rather than existing or not. There is a general attitude which tolerates some motivations for violence as "reasonable" while others are considered inappropriate or mistreatment. The unreasonable and unpredictable nature of male violence is typically associated with the language of powerlessness by the women. Consistent with this, attitudes described are aggressiveness on the part of the man, while submissiveness and politeness are associated to the woman.

\subsection{South Africa}

The microcredit program coupled with the discussion sessions in South Africa was targeted at identifying harmful gender norms with the objective of reducing violence. Included in the gender issues considered were cultural norms, domestic violence, sexuality, and HIVIAIDS status in addition to broader skill such as communication, conflict resolution, solidarity, leadership. The discussion sessions in South Africa were only for women. If successful in execution, women who participated in the discussion sessions would develop a better understanding of domestic violence and an explicit set of skills to reduce their own risk and exposure to violence. Though

\footnotetext{
${ }^{15}$ In the transcripts, the word 'moral' is used to qualify some types of violence. This seems to be an inaccurate translation from the French 'moral'. In French this part of speech may be both a noun and an adjective, and the noun may be both masculine and feminine, both with slightly different meanings. In the masculine acceptation it has the same meaning as the English 'mood'. This latter sense seems to be the one meant by the interviewees in this context. It will thus be substituted here by 'psychological', as this adjective best captures the meaning interviewees gave it

${ }^{16}$ In the transcript, the word 'nervous' is also found and is highly correlated with this theme. This is the other example of inaccurate translation from the French into English. In this case the original French word 'nerveux' means precisely irritable, irascible or, more commonly, angry.
} 
not explicitly targeted at other spheres of influence, the more general skills could be adapted to a range of other circumstance to more broadly increase women's decision making authority at home.

In testing the impact of the South Africa program, we find that participation in the discussion sessions reduced experience of violence in the previous year among women, compared to women in the control group by $23 \%$. There is no substantial change in decisions on household spending or purchases. Attitudes towards gender norms and violence did change with substantial, nearly 50 percent, increases in willingness to request condom use. There was no significant change in attitudes towards violence

\subsubsection{Verifying Randomization}

The IMAGE program in South Africa used a village cluster design to randomize. Assuming the clustering achieved randomization, we would expect no significant difference in pre-program outcome measures

\section{[INSERT TABLE 7 ABOUT HERE]}

Among the baseline measures of the outcomes we investigated (presented in Table 7), only three record differences between the discussion participant and the non-participant groups at or below the $5 \%$ significance level. One of these is from the group of indicators that measure attitudes to social norms: women in the non-participant group revealed themselves as more progressive than women in the discussion sessions, disagreeing on average more with the proposition that women should do all household chores; they also reported a more progressive attitude of the partner in relation to the woman's seeking health care for herself: the partners of women in the control group are on average reported as expecting to ask for permission less often than the partners of the women in the intervention group. However, women in the control group disagree more at baseline with the proposition that the wives are entitled to refuse sex if they are worried that their partner may have AIDS. As in the case of Burundi, given the large number of outcomes considered, it is not surprising to find a few cases of statistical differences at baseline.

\section{[INSERT TABLE 8 ABOUT HERE]}

Table 8 presents the comparison of socio-demographic characteristics of individuals in the IMAGE study. Of those characteristics considered, parity, access to sanitation in the house and access to electricity differ at the $5 \%$ level of significance between participant and non-participant group. We also consider the degree of connectedness as a proxy for baseline levels of entrepreneurship and initiative the women display. We measured connectedness as a count of the associations the women report being a member of at baseline. Connectedness does differ significantly between the two groups at the $1 \%$ level. To address baseline differences, we controlled for these variables in our regressions, in order to correct for these baseline differences between the two groups 


\subsubsection{Decision Making Authority}

Although the IMAGE intervention was targeted at gender roles and violence, the authors posited that such a directed program might have broader impacts on the role of women in the household. The hypothesis in SA-H1 was that women participating in the program would be more likely to participate in decision making in the household relative to women in control groups.

\section{[INSERT TABLE 9 ABOUT HERE]}

The results for decision making in South Africa are presented in Table 9. The decision making indicators often indicate a tendency towards increased decision making authority among discussion session participations but nearly all indicators are insignificant. The only indicators that mark a statistically significant positive change are the one capturing medium purchases for the home and the degree of controls the husband exerts over the money the respondent earns. Women appear to increase a decision making authority relative to the non-participant group baseline level. However, there appears to be no substantial difference in the post-program levels in the control and treatment group. Thus while decision making authority does appear to improve, it is ambiguous the extent to which such change is due to the IMAGE program rather than other environmental factors.

\subsubsection{Attitudes towards Gender Norms and Violence}

The primary target of the IMAGE study was to affect the set of gender norms and cultural practices that facilitate violence against women. Specifically, hypothesis SA-H2 was that women participating in the IMAGE program are more likely to exhibit gender norms that are more favorable for women.

Table 10 presents the results of the IMAGE program on attitudes toward gender norms shows that women in the treatment group are less likely to accept gender norms biased against women. In particular, treatment group participations are 12-15 percent more likely to reject tradition roles for women (e.g. women do all the household chores, obey if husband paid brideprice). Effects on attitudes towards fidelity and sex are much larger, showing a near 50 percent change. Subsequent to participation in discussion sessions, women become less tolerant of the husbands' other girlfriends, and are more open to the possibility of divorce, compared to control women at baseline, albeit none of the latter three changes reaches statistical significance. This is consistent women also being less likely to think that it is acceptable for a woman to refuse to have sex with her partner if he does not want to use a condom. Areas specifically targeted by the program do show substantial changes after the program. There is a 63 percent decline among participants who believe women can refuse sex if her husband refuses to wear a condom and a 50 percent decline in women believing that requesting her husband to use a condom indicates the woman is having an affair.

\section{[INSERT TABLE 10 ABOUT HERE]}


The measures of the acceptability of the husband's beating his wife were only measured at follow up for IMAGE. They depict a mixed picture, with women who participated in discussion sessions becoming less willing to accept that men beat their wife because she does not want to have sex or because she may be unfaithful; however, treated women become more likely to accept that a man beat his wife because she asks him to use a condom, or because she disagrees publicly with him. Overall the evidence on attitudes towards violence indicate only limited changes many of which are not statistically significant.

\subsubsection{Exposure to Violence}

The primary objective of the program was to reduce women's exposure to domestic violence. In contrast to the Burundi study, the IMAGE program was specifically targeted at reducing violence. As a result, the intervention was expected to substantially reduce violence. The specific hypothesis stated in SA- H3 was that women in the IMAGE program would be more likely to experience a reduction in the exposure to violence. Overall the results appear consistent with this hypothesis: the IMAGE intervention reduced violence among discussion series participants by $38 \%$ relative to the control group experienced at baseline, conditional on baseline values of women's parity, connectedness, and access to drinking water and sanitation. Compared to their own level at baseline, these women experienced a $34 \%$ reduction in the experience of violence.

\section{[INSERT FIGURE 7 ABOUT HERE]}

Breaking down the aggregate measure in its components, we observe that women in the control group also experienced a statistically significant reduction in the incidence of physical assault both in the form of their partner hitting them with a fist or an object; and of her pushing or shoving them. the third component of our aggregate measure of violence - experience of sexual assault in the form of forced sex - was also reduced, albeit not to a statistically significant extent. Finally, we included among the indicators of violence the measure of insult contained in the IMAGE survey that in fact here belongs to another group of indicators, and namely those aimed at detecting controlling behavior. The results are presented in Table 11.

\section{[INSERT TABLE 11 ABOUT HERE]}

Much of the violence reduction seems to come from declines in physical violence. To facilitate comparison to the Burundi results, we include a measure of 'insults' from the South Africa violence measurement tool. This is similar to the HITS indicator that was used in Burundi. In light of this, it is important to note that the question in the IMAGE questionnaire is worded slightly differently from the HITS questionnaire, asking as it does whether the respondent has been insulted or humiliated by her partner in public, rather than more generally insulted. Hence, for the same individual, the IMAGE question would elicits responses that are only a subset of the instances captured by the HITS indicator in Burundi. There is a marginal increase in the rate of insults among participants although there was an increase among the control group as well. This may suggest that violence shifted from physical to verbal after the intervention. It is 
important to note, however, that like in the case of Burundi, this may be because of differences in how the respondent categorizes violence.

\section{DISCUSSION}

The interventions we have studied here constitute two of the first randomized evaluations of the impact of microfinance products on domestic violence in sub-Saharan Africa. Concentrating only on female users, IMAGE explores the impact of the introduction of a microfinance and training product in a new market. The Burundi VSLA investigation explores the impact of training skills on a population that has self-selected for receiving microfinance services. Both programs sought to enhance women's decision making power, reduce acceptance of gendered social norms which facilitate domestic violence against women, and reduce exposure to such violence. The emphasis of the programs however differed in two key dimensions: first, the IMAGE program focused only on women while the Burundi program included both women and men. Second, the IMAGE program specifically targeted gender norms and violence while the Burundi program discussed household economic matters and issues in an effort to highlight and challenge traditional norms.

We find that both interventions had impacts on a range of desired indictors. In South Africa the IMAGE program is associated with a substantial decline in violence, and some changes in tolerance of gender-specific norms which facilitate violence. However, IMAGE appears to have had only limited impact on enhancing the role of women in decision making authority in the household. In Burundi on the other hand, there was substantial changes in household decision making authority over purchases and even fertility decisions by women but limited impact on decision making about sex. There were marginal changes in acceptability of violence. Violence was categorized in reasonable and unreasonable dimensions consistent with existing attitudes prevalent in Burundi. There were only marginal and often insignificant changes in exposure of women to domestic violence in Burundi. The findings suggest that discussion groups in conjunction with VSLA may empower women by increasing decision making authority over household purchases. The evidence suggests a trend towards potentially important improvements in reducing domestic violence. Beating one's wife, together with insulting and threatening her, seem to be the most common forms of violence. While, within the relatively brief study period physical violence did not significantly decrease, insults did, which may indicate reduced levels of violence and abuse within the household in the future.

Together these studies suggest a few key take-home messages: First, programs which target violence and do not incur backlash from the community may reduce exposure to violence (as in the case of South Africa). Second, in areas where it is infeasible to introduce gender-specific programming on violence, programs on economic factors may improve decision making authority and may aid in reducing violence, albeit to a lesser degree. Third, targeted programs tend to impact the areas in which they are targeted, whether that target is violence or economic decisions. Spillover effects to related areas appear to be insignificant. As a result, policy makers should be careful in assuming that limited programs will have broad effects across areas of decision making. 
The central message that emerges from both studies is that long-term ( $~ 5-10$ year) prospective studies are needed to assess the real efficacy of discussion group based interventions. Of critical importance is an assessment of whether impacts are permanent or decay over time and if periodic reinforcement help. The quantitative evidence indicate that in Burundi the greatest change in attitudes takes place in the management and access to resources, while in South Africa it is on violence. It should be noted that these results are not directly comparable, because of the different sub-populations the two interventions compare; it is however of interest to note that, in relation to the array of results both interventions measure, it is those they targeted most directly that record the greatest impact, at least in the short term. In both cases, longer term evaluations are warranted. Programs and evaluations should be designed to serve the purpose of assessing whether these initial results are maintained and broader effects in other areas reinforce the set of intended impacts. 


\section{References}

Aizer, Anna. 2010. "The Gender Wage Gap and Domestic Violence." American Economic Review, 100(4): 1847-59. DOI:10.1257/aer.100.4.1847

Ashraf, N., D. Karlan and W. Yin (2006). "Tying Odysseus to the Mast: Evidence from a Commitment Savings Product in the Philippines." Quarterly Journal of Economics 121(2): 673697

Becker, G. (1965) “A Theory of the Allocation of Time," Economic Journal 75 (299), p p. 493-51

Bozzoli, Belinda (with Mmanto Nkotsoe) (1990), The women of Phokeng: consciousness, life strategy, and migrancy in South Africa, Heinemann Educational Books, Inc.

Bowlus and Seitz (2006) Domestic Violence, Employment, And Divorce," International Economic Review 47(4), pages 1113-1149,

Browning and Chiappori (1998). "Efficient Intra-Household Allocations: A General Characterization and Empirical Tests," Econometrica, 66(6), pp 1241-1278

Duflo, E. (2003). "Grandmothers and Granddaughters: Old Age Pension and Intra- Household Allocation in South Africa." World Bank Economic Review 42: 1-25.

Dutton, Donald G; Corvo, Kenneth (2006) "Transforming a flawed policy: A call to revive psychology and science in domestic violence research and practice" Aggression and Violent Behavior 11: 457-483

Farmer and Tiefenthaler (1997) "An Economic Analysis of Domestic Violence." Review of Social Economy 55(3): 337-358

Garcia-Moreno, C., Jansen, Ellsberg, H.A.F.M., Heise, L., M., Watts, C., (2005) WHO Multicountry Study on Women's Health and Domestic Violence against Women, World Health Organization

Hargreaves, James R., Morison, L.A., Gear J.S.S., Makhubele M. B., Porter, J.D.H., Busza, j., Watts, C., Kim, J.C., Pronyk, P. M., (2007) "Hearing the Voices of the Poor": Assigning Poverty Lines on the Basis of Local Perceptions of Poverty. A Quantitative Analysis of Qualitative Data from Participatory Wealth Ranking in Rural South Africa", World Development, Vol. 35, No. 2, pp. 212-229

Johnson, Michael P. (1995) "Patriarchical Terrorism and Common Couple Violence: Two Forms of Violence against Women" Journal of Marriage and Family 57(2): 283-294

Johnson, Michael P; Ferraro, Kathleen J. (2000) "Research on Domestic Violence in the 1990s: Making Distinctions" Jouranl of Marriage and the Family 62: 948-963 
Kim; J; Ferrari; G, Abramsky; T, Watts; C, Hargreaves; J, Morison; L Phetla; G. Porter; J, Prony, $P$ (2009) "Assessing the incremental effects of combining economic and health interventions: the IMAGE study in South Africa" Bulletin of the World Health Organization vol.87 no.11 Genebra Nov.

Kim, J, Watts, C, Hargreaves, J, Ndhlovu, L, Phetla,G,. Morison, L Busza, J, Porter, J, Pronyk, $P$ (2007) "Understanding the Impact of a Microfinance-Based Intervention on Women's Empowerment and the Reduction of Intimate Partner Violence in South Africa" American Journal of Public Health, Vol 97, No. 10 October 1794-1802

Pollak, R. (2005). "Bargaining Power in Marriage: Earnings, Wage Rates and Household Production." NBER Working paper. 11239

Rangel, M. (2005). "Alimony Rights and Intrahousehold Allocation of Resources: Evidence from Brazil." The Economic Journal, 116 (July), 627-658

Sherin, K., Sinacore, J.M, Li, X-Q., Zitter, R.E., Shakil, A., (1998) "HITS: A Short Domestic Violence Screening Tool for Use in Family Practice Settings" Family Medicine, 30(7):508-12

Simanowitz, A., Nkuna, B., (1998), "Participatory Wealth Ranking Operational Manual", Tzaneen, Small Enterprise Foundation

Tauchen, Witte and Long (1991) "Domestic Violence: a Non-Random Affair" NBER Working Paper Series. w1665

Strauss, J. and Thomas, D (1995). "Empirical Modeling of Household and Family Decisions," Papers 95-12, RAND Reprint series 


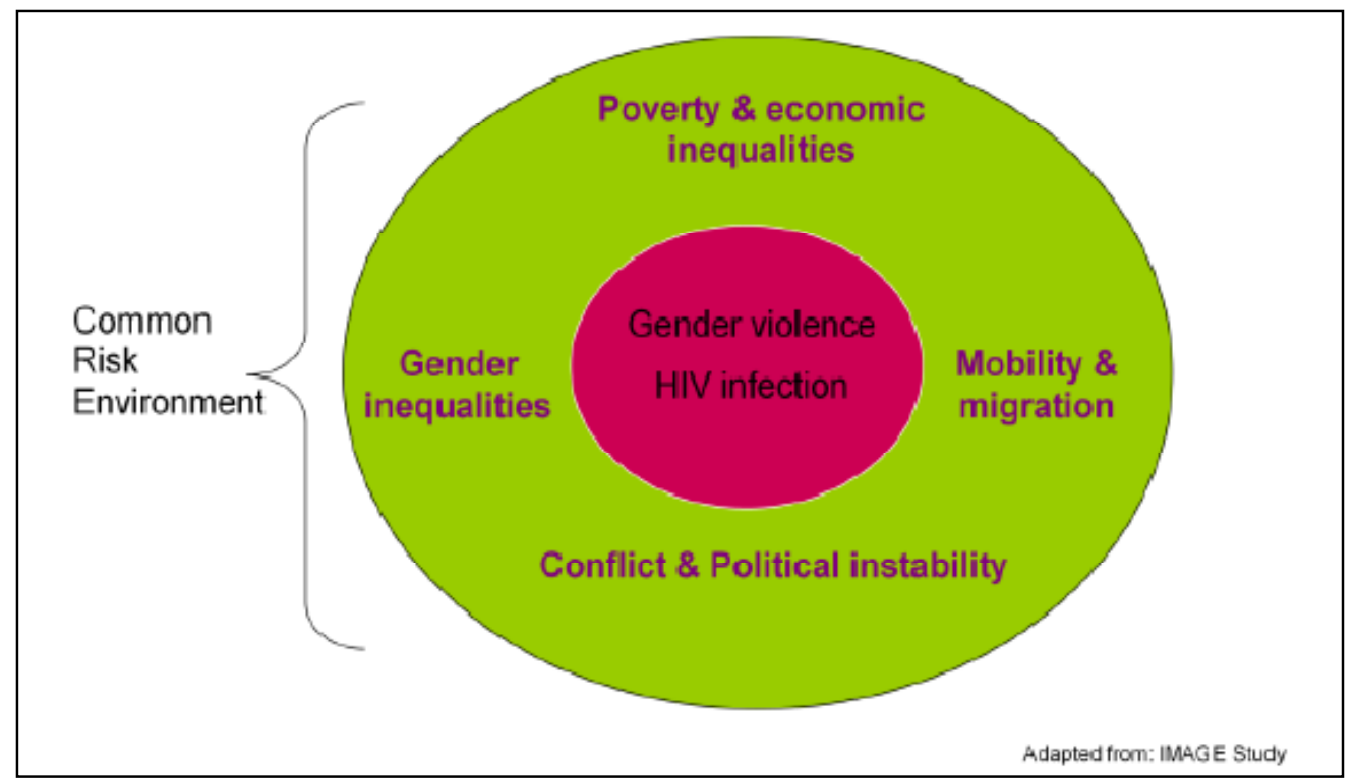

Figure 1 Theoretical framework of the IMAGE study (South Africa)

Notes: Based on figure from IMAGE study results (Kim et al., 2009). A subsequent cross-sectional study compared the two initial groups at follow up with a third group of women in similar villages that only had access to microfinance (not depicted here) 

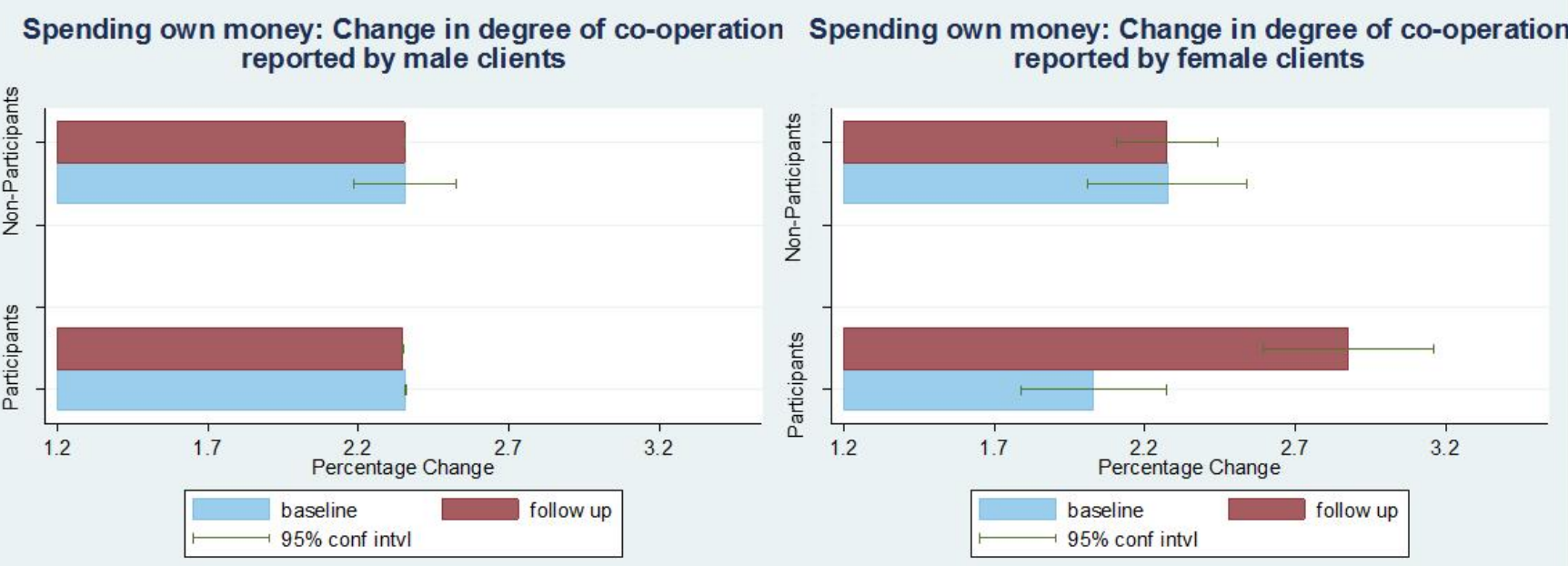

Figure 2. Decision Making on Economic Issues: Who decides how to spend money? (Burundi) Notes: Outcome measures based on survey data collected with assistance of the International Rescue Committee - Burundi. Participants refer to individuals randomly selected to attend the program that consisted of set of 6 discussion sessions. Non-Participants refer to individuals who did not attend the program. Confidence intervals are based on village-cluster estimated standard errors. 

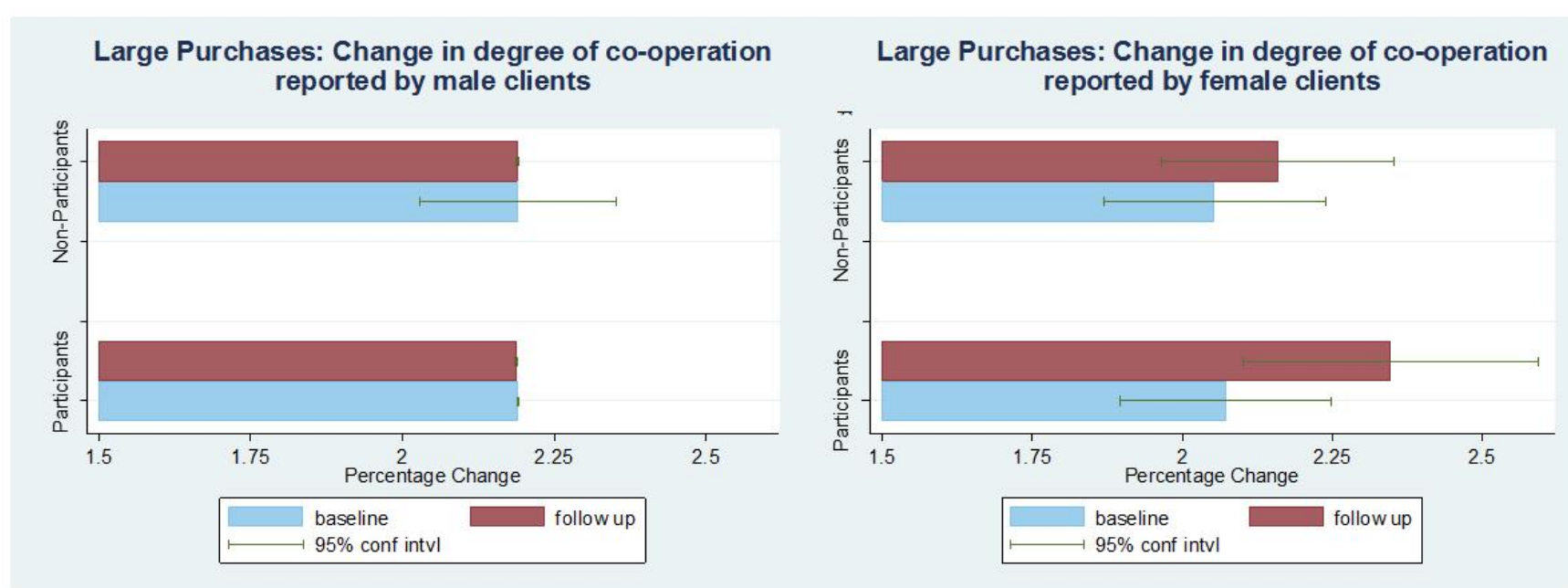

Figure 3. Decision Making on Economic Issues: Who decides on large household purchases? (Burundi) Notes: Outcome measures based on survey data collected with assistance of the International Rescue Committee - Burundi. Participants refer to individuals randomly selected to attend the program that consisted of set of 6 discussion sessions. Non-Participants refer to individuals who did not attend the program. Confidence intervals are based on village-cluster estimated standard errors. 
Having Kids: Change in degree of co-operation reported by male clients

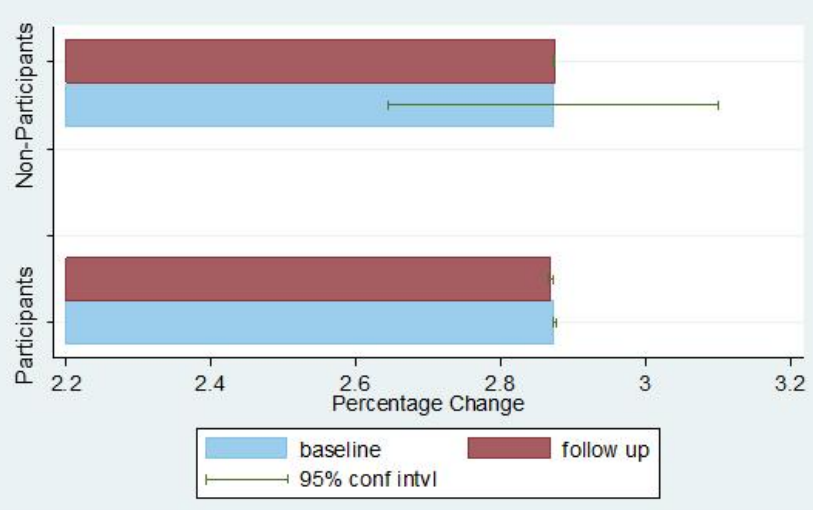

Having Kids: Change in degree of co-operation reported by female clients

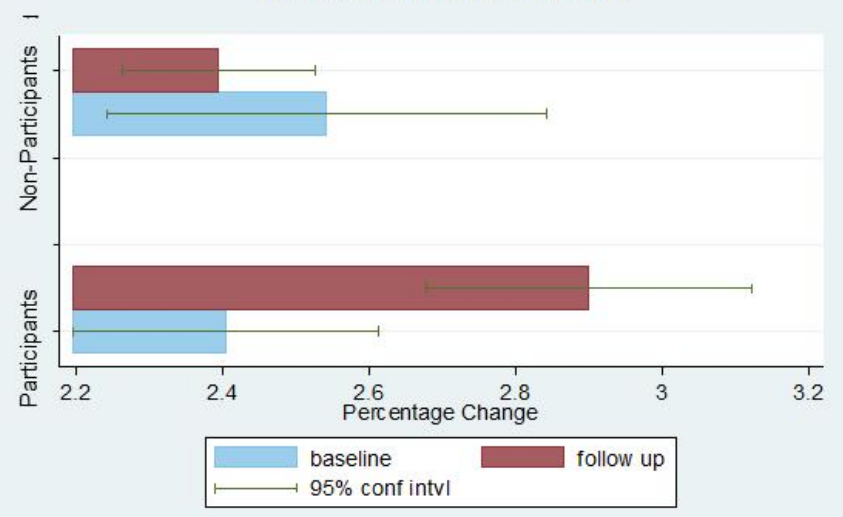

Figure 4. Decision Making on Household Issues: Who decides on having children? (Burundi)

Notes: Outcome measures based on survey data collected with assistance of the International Rescue Committee - Burundi Participants refer to individuals randomly selected to attend the program that consisted of set of 6 discussion sessions. Non-Participants refer to individuals who did not attend the program. Confidence intervals are based on village-cluster estimated standard errors. 
Change in percent of male respondents who disagree it is ok to beat wife if she refuses sex

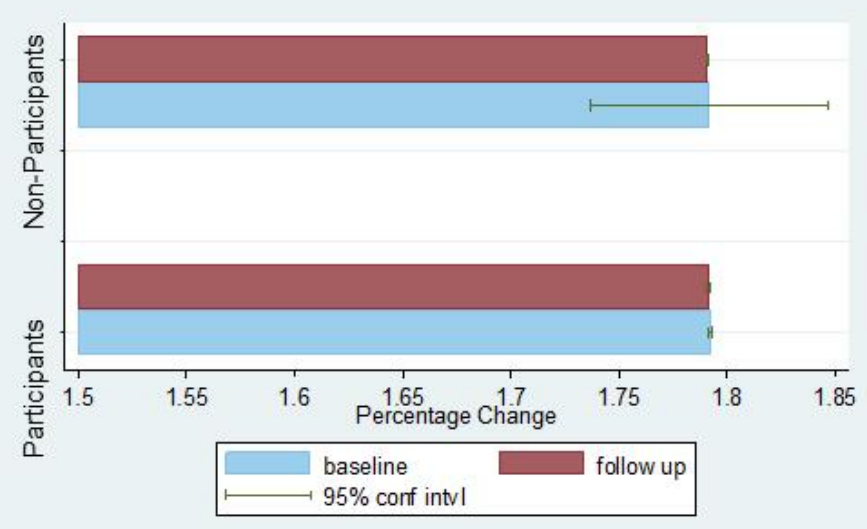

Change in percent of female respondents who disagree it is ok to beat wife if she refuses sex

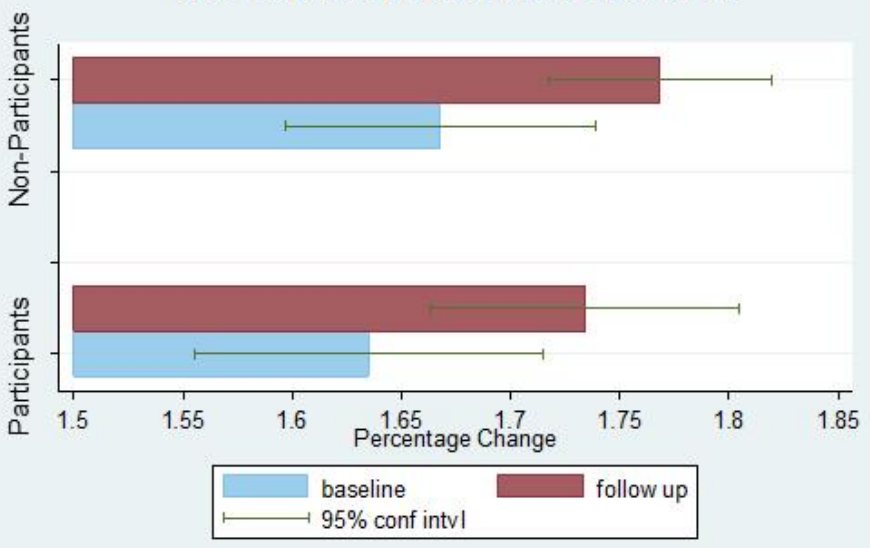

Figure 5.Attitudes towards violence: Acceptability of abuse if wife refuses sex (Burundi)

Notes: Outcome measures based on survey data collected with assistance of the International Rescue Committee - Burundi. Participants refer to individuals randomly selected to attend the program that consisted of set of 6 discussion sessions. Non-Participants refer to individuals who did not attend the program. Confidence intervals are based on village-cluster estimated standard errors. 
Change in percent of male respondents who disagree it is ok to beat wife if she neglects the kids

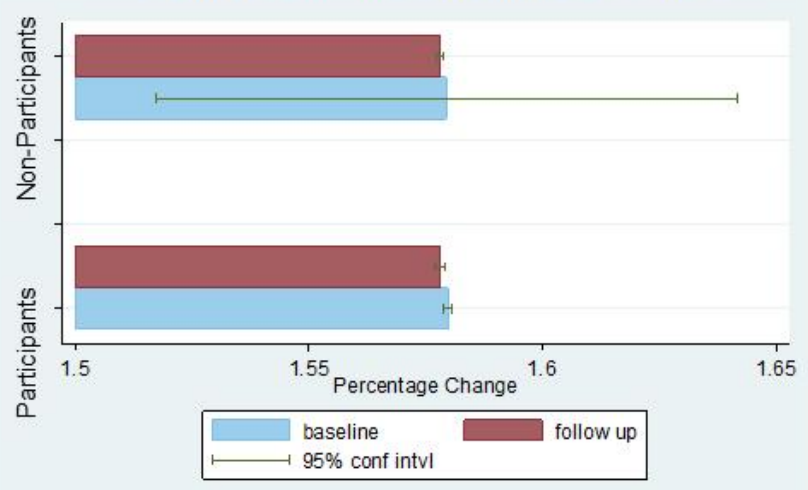

Change in percent of fem ale respondents who disagree it is ok to beat wife if she neglects the kids

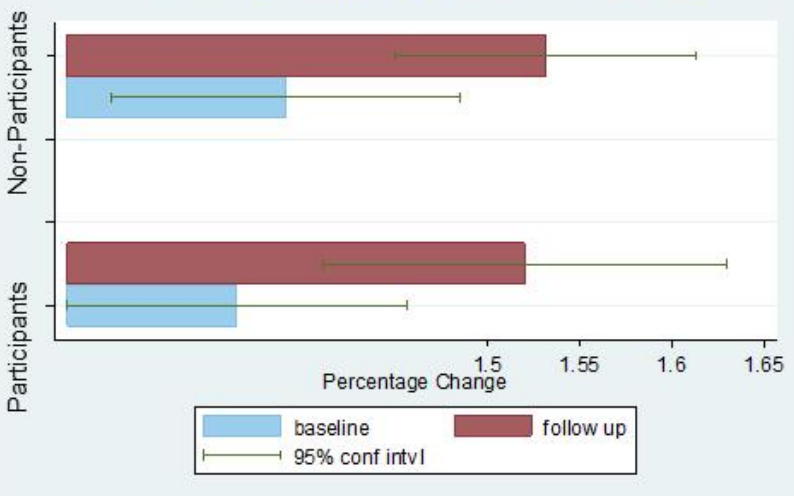

Figure 6.Attitudes towards violence: Acceptability of abuse if wife neglects children (Burundi)

Notes: Outcome measures based on survey data collected with assistance of the International Rescue Committee - Burundi. Participants refer to individuals randomly selected to attend the program that consisted of set of 6 discussion sessions. Non-Participants refer to individuals who did not attend the program. Confidence intervals are based on village-cluster estimated standard errors. 


\section{Change in percent of respondents who do not ask partner's permission for medium purchases for the home}

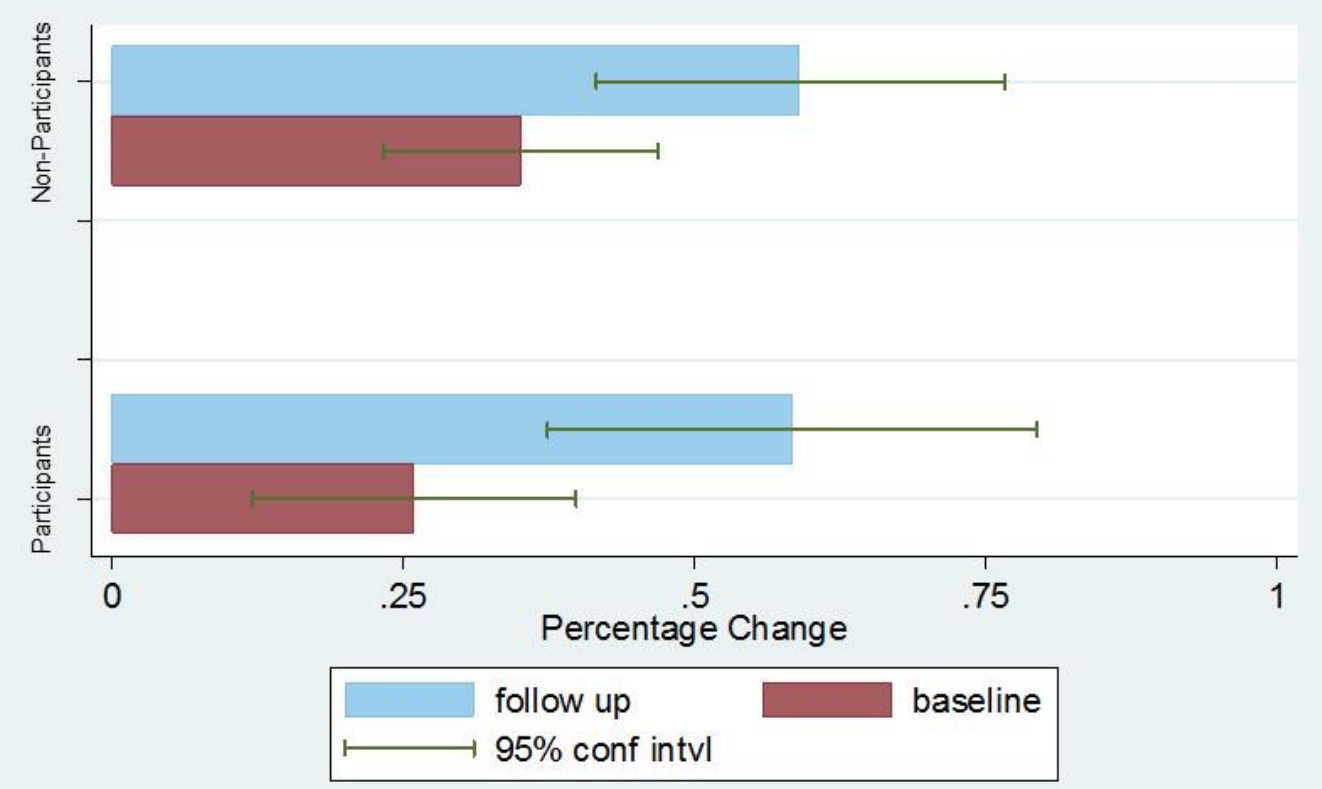

Figure 7. Change in Violence Exposure over the previous 12 months (South Africa)

Notes: Outcome measures based on survey data collected by Intervention with Microfinance for Gender Equity (IMAGE) in South Africa, a cooperative study between the London School of Hygiene and Tropical Medicine (LSHTM), Wits University in Johannesburg, and the microfinance NGO Small Enterprise Foundation (SEF). Results have been presented in Kim et al (2009). Estimates shown here based on authors' own calculations from the data in Kim et. al. (2009). Participants refer to individuals randomly selected to attend a program consisting of a set of 10 discussion sessions. Non-Participants refer to individuals who did not attend the program. Confidence intervals are based on village-cluster estimated standard errors. 
Table 1. Comparison of Baseline Levels of Decision Making, Attitudes and Violence Between Control and Program Participation Groups (Burundi)

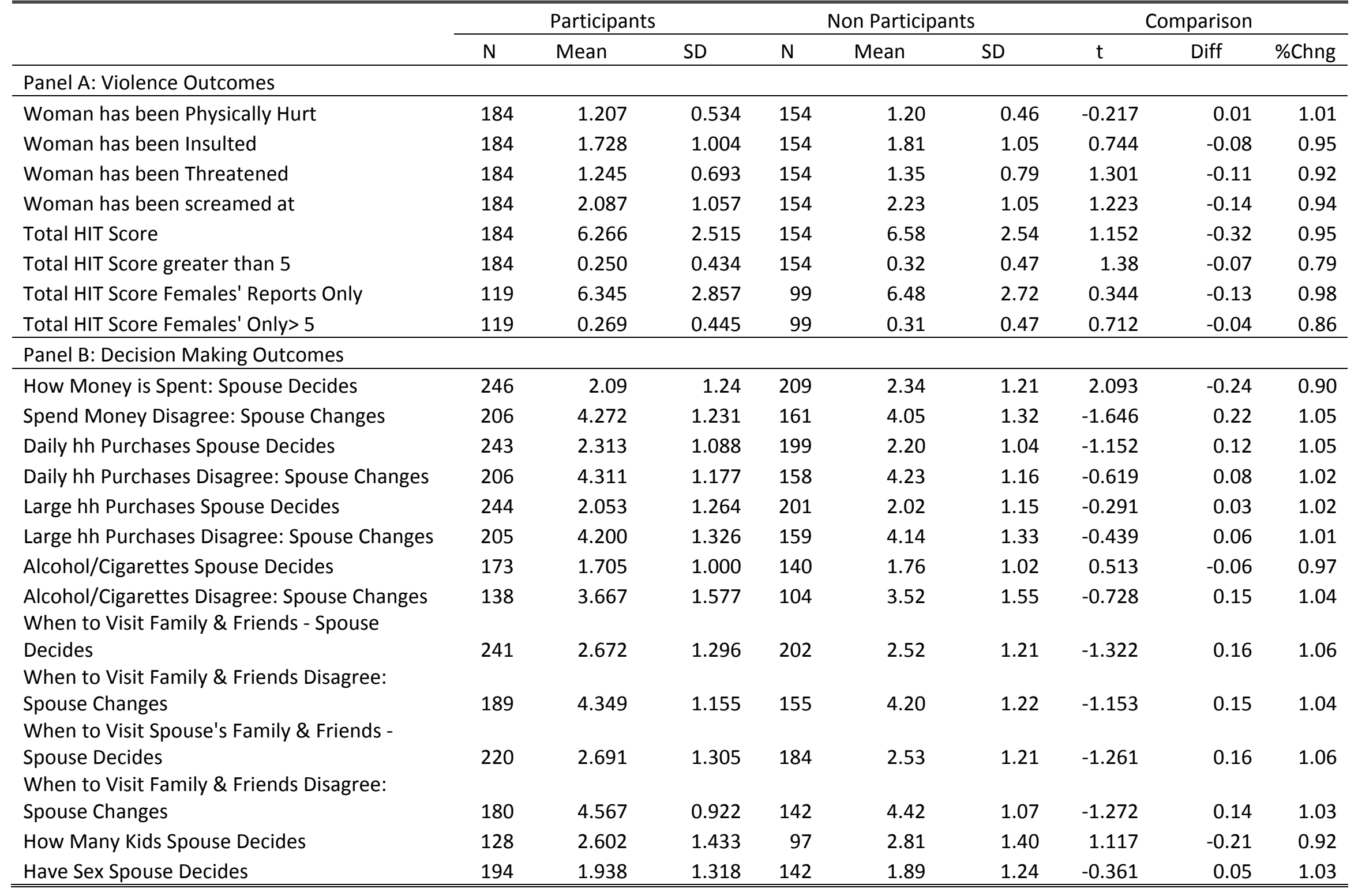




\begin{tabular}{|c|c|c|c|c|c|c|c|c|c|}
\hline $\begin{array}{l}\text { When to Visit Family \& Friends Disagree: } \\
\text { Spouse Changes }\end{array}$ & 110 & 4.555 & 0.982 & 82 & 4.26 & 1.26 & -1.784 & 0.30 & 1.07 \\
\hline Women should do as Men Say & 257 & 2.202 & 0.571 & 225 & 2.13 & 0.56 & -1.418 & 0.07 & 1.03 \\
\hline Okay for husband to abandon wife if he wants & 257 & 2.467 & 0.599 & 225 & 2.45 & 0.63 & -0.241 & 0.01 & 1.01 \\
\hline Woman's job to gather water, even if unsafe & 257 & 2.486 & 0.560 & 225 & 2.45 & 0.54 & -0.658 & 0.03 & 1.01 \\
\hline wants & 256 & 2.773 & 0.759 & 222 & 2.66 & 0.75 & -1.611 & 0.11 & 1.04 \\
\hline $\begin{array}{l}\text { Okay to beat wife if goes out w/out telling } \\
\text { husband }\end{array}$ & 254 & 1.630 & 0.484 & 223 & 1.58 & 0.50 & -1.145 & 0.05 & 1.03 \\
\hline Okay to beat wife if neglects kids & 257 & 1.455 & 0.499 & 224 & 1.48 & 0.50 & 0.491 & -0.02 & 0.98 \\
\hline Okay to beat wife if argues w/ husband & 254 & 1.736 & 0.442 & 221 & 1.74 & 0.44 & 0.145 & -0.01 & 1.00 \\
\hline Okay to beat wife for any reason & 257 & 1.864 & 0.344 & 224 & 1.89 & 0.31 & 0.974 & -0.03 & 0.98 \\
\hline Never okay to beat wife & 255 & 1.525 & 0.500 & 222 & 1.53 & 0.50 & 0.033 & -0.00 & 1.00 \\
\hline \multicolumn{10}{|l|}{ Panel D: Consumption } \\
\hline Weekly Consumption (value) & 241 & $13,379.3$ & $15,372.22$ & 200 & $11,291.93$ & $11,592.24$ & -1.624 & $2,087.33$ & 1.18 \\
\hline Weekly Self-production (value) & 192 & $5,646.2$ & $6,140.84$ & 150 & $4,901.47$ & $4,689.70$ & -1.272 & 744.73 & 1.15 \\
\hline Yearly Consumption (value) & 257 & $1,360,000$ & $1,630,000$ & 226 & $1,140,000$ & $1,500,000$ & -1.524 & 220,000 & 1.19 \\
\hline Rights for women to own and inherit land & 257 & 0.9 & 1.23 & 224 & 0.74 & 0.72 & -1.661 & 0.15 & 1.20 \\
\hline Women reps in reconstruction programs & 257 & 1.0 & - - & 224 & 1.00 & -- & -- & -- & -- \\
\hline Women reps in local community meetings & 257 & 1.0 & 0.50 & 224 & 0.99 & 0.09 & -1.261 & 0.04 & 1.04 \\
\hline Increased penalties for spousal abuse & 257 & 1.0 & 0.15 & 224 & 0.97 & 0.16 & -0.240 & 0.00 & 1.00 \\
\hline
\end{tabular}

Notes: Outcome measures based on survey data collected with assistance of the International Rescue Committee - Burundi.

Participants refer to individuals randomly selected to attend the program that consisted of a set of 6 discussion sessions. Non-

Participants refer to individuals who did not attend the program. Confidence intervals are based on village-cluster estimated 
standard errors. Number of respondents varies due to differential response rates to questions. Comparison columns report mean difference between participant and non-participant groups. Also reported are the t-statistics testing if this difference is distinguishable from zero. 
Table 2. Comparison of Baseline Levels of Sociodemographic Characteristics Between Control and Program Participation Groups (Burundi)

\begin{tabular}{|c|c|c|c|c|c|c|c|c|c|}
\hline \multirow[b]{2}{*}{ Variable } & \multicolumn{3}{|c|}{ Participants } & \multicolumn{3}{|c|}{ Non Participants } & \multicolumn{3}{|c|}{ Comparison } \\
\hline & $\mathrm{N}$ & Mean & SD & $\mathrm{N}$ & Mean & SD & $\mathrm{t}$ & Diff & \%Change \\
\hline Males & 257 & 0.401 & 0.491 & 226 & 0.336 & 0.473 & -1.468 & 0.065 & 0.16 \\
\hline Age & 256 & 39 & 12.395 & 226 & 37 & 13.209 & -1.31 & 1.534 & 0.04 \\
\hline Respondents' Level of schooling & 174 & 0.897 & 0.305 & 148 & 0.892 & 0.312 & -0.135 & 0.005 & 0.01 \\
\hline Spouse's Level of Schooling & 137 & 0.912 & 0.284 & 116 & 0.905 & 0.294 & -0.198 & 0.007 & 0.01 \\
\hline Displaced & 254 & 0.996 & 0.063 & 222 & 0.995 & 0.067 & -0.095 & 0.001 & 0.00 \\
\hline Displaced outside Burundi & 239 & 0.402 & 0.491 & 207 & 0.391 & 0.489 & -0.223 & 0.011 & 0.03 \\
\hline Respondent Half Hectares & 175 & 2.061 & 1.617 & 149 & 1.935 & 1.666 & -0.688 & 0.126 & 0.06 \\
\hline Spouse's Half Hectares & 115 & 1.935 & 1.427 & 93 & 1.949 & 1.726 & 0.063 & -0.014 & -0.01 \\
\hline Use Others' Land & 129 & 0.744 & 0.438 & 109 & 0.761 & 0.428 & 0.307 & -0.017 & -0.02 \\
\hline Respondent \& Spouse Own Land & & & & & & & & & \\
\hline Jointly & 257 & 0.412 & 0.493 & 226 & 0.345 & 0.476 & -1.524 & 0.067 & 0.16 \\
\hline
\end{tabular}

Notes: Outcome measures based on baseline survey data collected with assistance of the International Rescue Committee Burundi. Participants refer to individuals randomly selected to attend the program that consisted of a set of 6 discussion sessions. Non-Participants refer to individuals who did not attend the program. Confidence intervals are based on villagecluster estimated standard errors. Number of respondents varies due to differential response rates to questions. Comparison columns report mean difference between participant and non-participant groups. Also reported are the t-statistics testing if this difference is distinguishable from zero. 
Table 3. Comparison of Pre-Program Decision Making and Dispute Resolution Behavior (Burundi)

\begin{tabular}{|c|c|c|c|c|}
\hline & \multicolumn{2}{|c|}{ Non-Participants } & \multicolumn{2}{|c|}{ Participants } \\
\hline & females & males & females & males \\
\hline \multicolumn{5}{|l|}{ Panel A: Decision Making Authority over Household Decisions } \\
\hline \multirow[t]{2}{*}{ How money you earn is spent } & $2.276 * * *$ & 0.0790 & $-0.247^{* *}$ & $0.00247^{* *}$ \\
\hline & $(0.128)$ & $(0.0826)$ & $(0.117)$ & $(0.00118)$ \\
\hline \multirow[t]{2}{*}{ Major household purchases } & $2.054 * * *$ & $0.136^{*}$ & 0.0186 & -0.000184 \\
\hline & $(0.0897)$ & $(0.0786)$ & $(0.0858)$ & $(0.000866)$ \\
\hline \multirow[t]{2}{*}{ Daily household purchases } & $2.213^{* * *}$ & -0.0712 & 0.112 & -0.00113 \\
\hline & $(0.0892)$ & $(0.0621)$ & $(0.0919)$ & $(0.000925)$ \\
\hline \multirow[t]{2}{*}{ Purchases of alcohol and cigarettes } & $1.725^{* * *}$ & $-0.151 *$ & -0.0449 & 0.000459 \\
\hline & $(0.0752)$ & $(0.0812)$ & $(0.0863)$ & $(0.000870)$ \\
\hline \multirow[t]{2}{*}{ Visits your family or friends } & $2.393 * * *$ & 0.121 & 0.145 & -0.00152 \\
\hline & $(0.109)$ & $(0.0919)$ & $(0.0977)$ & $(0.000992)$ \\
\hline \multirow[t]{2}{*}{ Visits your spouse's family or friends } & $2.442 * * *$ & $0.114^{*}$ & 0.131 & -0.00134 \\
\hline & $(0.0988)$ & $(0.0625)$ & $(0.0810)$ & $(0.000812)$ \\
\hline \multirow[t]{2}{*}{ How many children to have } & $2.542 * * *$ & $0.331 * * *$ & -0.137 & 0.00138 \\
\hline & $(0.146)$ & $(0.111)$ & $(0.102)$ & $(0.00102)$ \\
\hline \multirow[t]{2}{*}{ When to have sex } & $1.649 * * *$ & $0.556 * * *$ & 0.0212 & -0.000201 \\
\hline & $(0.0978)$ & $(0.0738)$ & $(0.0913)$ & $(0.000913)$ \\
\hline \multicolumn{5}{|c|}{ Panel B: Dispute Resolution over Disagreements on Household Decisions (No dispute because Spouse knows better) } \\
\hline \multirow[t]{2}{*}{ Disagree $w$ spouse on how money is spent } & $4.074 * * *$ & 0.137 & $0.210 * *$ & $-0.00212 * *$ \\
\hline & $(0.136)$ & $(0.0953)$ & $(0.101)$ & $(0.00102)$ \\
\hline \multirow[t]{2}{*}{ Disagree w spouse on major hh purchases } & $4.159 * * *$ & 0.150 & 0.0540 & -0.000561 \\
\hline & $(0.161)$ & $(0.0906)$ & $(0.126)$ & $(0.00127)$ \\
\hline \multirow[t]{2}{*}{ Disagree w spouse on daily hh purchases } & $4.175^{* * *}$ & $0.259 * *$ & 0.0539 & -0.000562 \\
\hline & $(0.135)$ & $(0.111)$ & $(0.122)$ & $(0.00123)$ \\
\hline \multirow[t]{2}{*}{ Disagree w spouse on purchases of alcohol and cigarettes } & $3.639 * * *$ & $-0.315^{* *}$ & 0.123 & -0.00124 \\
\hline & $(0.115)$ & $(0.145)$ & $(0.156)$ & $(0.00156)$ \\
\hline Disagree w spouse on visit your spouse's family or friends & $4.387^{* * *}$ & $0.200 * * *$ & 0.119 & -0.00119 \\
\hline
\end{tabular}


Disagree w spouse on visit your family or friends

Disagree on having sex
(0.0996)

$4.243^{* * *}$

$(0.113)$
$4.144 * * *$

(0.113)
(0.0607)

0.130

(0.0919)

$-0.293 * * *$

(0.0731)
(0.0936)

0.141

(0.138)

$0.275^{* *}$

(0.107)
(0.000951)

$-0.00143$

(0.00138)

$-0.00275^{* *}$

(0.00108)

Notes: Robust standard errors clustered at the village level are reported in parentheses. Results that are significant at the 0.05 $(0.10,0.01)$ level are marked with a $* *(*, * * *)$. Outcome variable in Panel A is an indicator variable that is 1 if the decision was taken unilaterally by the respondent. Outcome variable in Panel B is an indicator variable that is 1 if there was no discussion because the respondent believes their spouse knows better for each of the categories listed in the panel. Participants refer to individuals randomly selected to attend the program that consisted of a set of 6 discussion sessions. Non-Participants refer to individuals who did not attend the program. 
Table 4. Estimated Effect of Discussion Sessions on Decision Making and Dispute Resolution Outcomes (Burundi)

\begin{tabular}{|c|c|c|c|c|}
\hline & \multicolumn{2}{|c|}{ Non-Participants } & \multicolumn{2}{|c|}{ Participants } \\
\hline & females & males & females & males \\
\hline \multicolumn{5}{|c|}{ Panel A: Decision Making Authority over Household Decisions (=1 if Respondents decide alone) } \\
\hline \multirow[t]{2}{*}{ How money you earn is spent } & -0.00272 & $4.37 e-05$ & $0.602 * * *$ & $-0.00605 * * *$ \\
\hline & $(0.0817)$ & $(0.000822)$ & $(0.138)$ & $(0.00138)$ \\
\hline$\%$ change (relative to female baseline) & $-0.01 \%$ & $0.00 \%$ & $26.45 \% * * *$ & $-0.27 \% * * *$ \\
\hline \multirow[t]{2}{*}{ Major hh purchases } & 0.106 & -0.00104 & $0.293 * *$ & $-0.00293 * *$ \\
\hline & $(0.0942)$ & $(0.000938)$ & $(0.119)$ & $(0.00120)$ \\
\hline$\%$ change (relative to female baseline) & $5.16 \%$ & $-0.05 \%$ & $14.26 \% * *$ & $-0.14 \% * * *$ \\
\hline \multirow[t]{2}{*}{ Daily hh purchases } & 0.0818 & -0.000803 & 0.0927 & -0.000924 \\
\hline & $(0.0770)$ & $(0.000776)$ & $(0.115)$ & $(0.00116)$ \\
\hline$\%$ change (relative to female baseline) & $3.70 \%$ & $-0.04 \%$ & $4.19 \%$ & $-0.04 \%$ \\
\hline \multirow[t]{2}{*}{ Purchases of alcohol and cigarettes } & 0.0132 & -0.000103 & 0.0156 & -0.000158 \\
\hline & $(0.0860)$ & $(0.000866)$ & $(0.127)$ & $(0.00128)$ \\
\hline$\%$ change (relative to female baseline) & $0.90 \%$ & $-0.01 \%$ & $0.90 \%$ & $-0.01 \%$ \\
\hline \multirow[t]{2}{*}{ Visit your family or friends } & $0.232 * *$ & $-0.00232 * *$ & 0.0836 & -0.000772 \\
\hline & $(0.0961)$ & $(0.000962)$ & $(0.144)$ & $(0.00145)$ \\
\hline$\%$ change (relative to female baseline) & $9.69 \% * *$ & $-0.10 \% * *$ & $3.49 \%$ & $-0.32 \%$ \\
\hline \multirow[t]{2}{*}{ Visit your spouse's family or friends } & -0.0367 & 0.000351 & 0.0563 & -0.000525 \\
\hline & $(0.0776)$ & $(0.000787)$ & $(0.0900)$ & $(0.000913)$ \\
\hline$\%$ change (relative to female baseline) & $-1.50 \%$ & $0.01 \%$ & $2.31 \%$ & $-0.02 \%$ \\
\hline \multirow[t]{2}{*}{ How many children to have } & $-0.147^{* *}$ & $0.00149 * *$ & $0.359 * * *$ & $-0.00359 * * *$ \\
\hline & $(0.0639)$ & $(0.000645)$ & $(0.108)$ & (0.00109) \\
\hline$\%$ change (relative to female baseline) & $-5.78 \% * *$ & $0.06 \% * *$ & $14.12 \% * * *$ & $-0.14 \% * * *$ \\
\hline Having sex & 0.0118 & -0.000115 & 0.104 & -0.00102 \\
\hline
\end{tabular}




\begin{tabular}{|c|c|c|c|c|}
\hline \multirow{2}{*}{$\%$ change (relative to female baseline) } & $(0.0748)$ & $(0.000750)$ & (0.0949) & (0.000954) \\
\hline & $0.72 \%$ & $-0.01 \%$ & $6.31 \%$ & $-0.06 \%$ \\
\hline \multicolumn{5}{|c|}{ Panel B: Dispute Resolution over Disagreements on Household Decisions (=1 if there was no dispute because respondent feels spouse knows better) } \\
\hline \multirow[t]{2}{*}{ Disagree w spouse on major hh purchases } & 0.183 & 0.00104 & 0.183 & -0.00184 \\
\hline & (0.135) & $(0.00152)$ & (0.135) & $(0.00135)$ \\
\hline$\%$ change (relative to female baseline) & $4.40 \%$ & $0.03 \%$ & $4.40 \%$ & $-0.04 \%$ \\
\hline \multirow[t]{2}{*}{ Disagree w spouse on how money is spent } & -0.00814 & $8.84 e-05$ & -0.00253 & $3.37 e-05$ \\
\hline & $(0.139)$ & $(0.00139)$ & $(0.147)$ & $(0.00148)$ \\
\hline$\%$ change (relative to female baseline) & $-0.20 \%$ & $0.00 \%$ & $-0.06 \%$ & $0.00 \%$ \\
\hline \multirow[t]{2}{*}{ Disagree w spouse on daily hh purchases } & $-0.213^{*}$ & $0.00216^{*}$ & 0.0474 & -0.000477 \\
\hline & (0.109) & $(0.00110)$ & (0.119) & (0.00119) \\
\hline$\%$ change (relative to female baseline) & $-5.10 \% *$ & $0.05 \% *$ & $1.14 \%$ & $-0.01 \%$ \\
\hline \multirow[t]{2}{*}{ Disagree w spouse on purchases of alcohol and cigarettes } & -0.0731 & 0.000747 & -0.0404 & 0.000406 \\
\hline & $(0.125)$ & $(0.00124)$ & (0.209) & (0.00209) \\
\hline$\%$ change (relative to female baseline) & $-2.01 \%$ & $0.02 \%$ & $-1.11 \%$ & $0.01 \%$ \\
\hline \multirow[t]{2}{*}{ Disagree w spouse on visit your family or friends } & -0.0341 & 0.000367 & 0.0658 & -0.000667 \\
\hline & $(0.108)$ & (0.00109) & $(0.165)$ & $(0.00165)$ \\
\hline$\%$ change (relative to female baseline) & $-0.80 \%$ & $0.01 \%$ & $1.55 \%$ & $-0.02 \%$ \\
\hline \multirow[t]{2}{*}{ Disagree w spouse on visit your spouse's family or friends } & 0.124 & -0.00126 & 0.0154 & -0.000174 \\
\hline & $(0.0891)$ & $(0.000902)$ & (0.109) & $(0.00111)$ \\
\hline$\%$ change (relative to female baseline) & $2.83 \%$ & $-0.03 \%$ & $0.35 \%$ & $0.00 \%$ \\
\hline \multirow[t]{2}{*}{ Disagree on having sex } & $-0.868 * * *$ & $0.00876 * * *$ & -0.0710 & 0.000688 \\
\hline & $(0.133)$ & $(0.00134)$ & $(0.148)$ & $(0.00149)$ \\
\hline$\%$ change (relative to female baseline) & $-20.95 \% * * *$ & $0.21 \% * * *$ & $-1.71 \%$ & $0.02 \%$ \\
\hline
\end{tabular}

Notes: Robust standard errors clustered at the village level are reported in parentheses. Results that are significant at the $0.05(0.10$,

0.01 ) level are marked with a ${ }^{* *}(*, * * *)$. Outcome variable in Panel $\mathrm{A}$ is an indicator variable that is 1 if the decision was taken

unilaterally by the respondent for each of the categories listed in the panel. Outcome variable in Panel B is an indicator variable that is 1 
if there was no discussion because the respondent believes their spouse knows better for each of the categories listed in the panel. Participants refer to individuals randomly selected to attend the program that consisted of a set of 6 discussion sessions. Non-

Participants refer to individuals who did not attend the program. 
Table 5. Estimated Effect of Discussion Sessions on Attitudes towards Gender Norms and Violence (Burundi)

\begin{tabular}{|c|c|c|c|c|}
\hline & \multicolumn{2}{|c|}{ Non-Participants } & \multicolumn{2}{|c|}{ Participants } \\
\hline & females & males & females & males \\
\hline \multicolumn{5}{|l|}{ Panel A: Baseline } \\
\hline$=1$ if Agree that it's acceptable to beat ones wife & $1.475^{* * *}$ & $0.176^{* * *}$ & 0.0476 & -0.000490 \\
\hline if she goes out without her husband's permission & $(0.0375)$ & $(0.0281)$ & $(0.0432)$ & $(0.000437)$ \\
\hline \multirow[t]{2}{*}{$=1$ if Agree that it's acceptable to beat ones wife if she neglects kids } & $1.390^{* * *}$ & $0.189 * * *$ & -0.0262 & 0.000271 \\
\hline & $(0.0459)$ & $(0.0302)$ & (0.0449) & $(0.000451)$ \\
\hline \multirow[t]{2}{*}{$=1$ if Agree that it's acceptable to beat ones wife if she argues } & $1.724 * * *$ & $0.0478^{* *}$ & -0.00899 & 0.000106 \\
\hline & $(0.0387)$ & $(0.0223)$ & $(0.0467)$ & $(0.000473)$ \\
\hline \multirow[t]{2}{*}{$=1$ if Agree that it's acceptable to beat ones wife if she refuses sex } & $1.668 * * *$ & $0.124 * * *$ & -0.0328 & 0.000335 \\
\hline & $(0.0345)$ & $(0.0268)$ & $(0.0387)$ & $(0.000393)$ \\
\hline \multirow[t]{2}{*}{$=1$ if Agree that it's acceptable to beat ones wife if she burns food } & $0.203^{* *}$ & -0.00739 & -0.0525 & 0.000535 \\
\hline & $(0.0797)$ & $(0.0173)$ & $(0.0653)$ & $(0.000666)$ \\
\hline \multirow[t]{2}{*}{$=1$ if Agree that it's acceptable to beat ones wife if she annoying } & $1.854 * * *$ & $0.0540 * * *$ & -0.0160 & 0.000158 \\
\hline & $(0.0199)$ & $(0.0160)$ & $(0.0354)$ & $(0.000357)$ \\
\hline \multirow[t]{2}{*}{$=1$ if Agree that it's acceptable to beat ones wife for any reason } & $1.866^{* * *}$ & $0.0385^{*}$ & -0.0292 & 0.000297 \\
\hline & $(0.0239)$ & $(0.0190)$ & (0.0328) & $(0.000332)$ \\
\hline \multirow{2}{*}{$\begin{array}{l}=1 \text { if Agree that it's acceptable to beat ones wife that it's never ok to beat } \\
\text { wife }\end{array}$} & $1.617^{* * *}$ & $-0.0986 * *$ & -0.00332 & $3.49 e-05$ \\
\hline & $(0.0421)$ & (0.0398) & $(0.0556)$ & $(0.000561)$ \\
\hline \multicolumn{5}{|l|}{ Panel B: Post-Program } \\
\hline$=1$ if Agree that it's acceptable to beat ones wife & $0.187^{* * *}$ & $-0.00191 * * *$ & 0.0223 & -0.000222 \\
\hline if she goes out without her husband's permission & $(0.0384)$ & $(0.000390)$ & $(0.0380)$ & $(0.000386)$ \\
\hline$\%$ change (relative to female baseline) & $12.68 \% * * *$ & $-0.13 \% * * *$ & $1.51 \%$ & $-0.02 \%$ \\
\hline \multirow[t]{2}{*}{$=1$ if Agree that it's acceptable to beat ones wife if she neglects kids } & $0.141^{* * *}$ & $-0.00143^{* * *}$ & $0.130^{* *}$ & $-0.00132 * *$ \\
\hline & (0.0398) & $(0.000404)$ & (0.0533) & $(0.000538)$ \\
\hline
\end{tabular}




\begin{tabular}{|c|c|c|c|c|}
\hline \% change (relative to female baseline) & $10.14 \% * * *$ & $-0.10 \% * * *$ & $9.35 \%$ & $-0.09 \%$ \\
\hline \multirow{2}{*}{$=1$ if Agree that it's acceptable to beat ones wife if she argues } & $0.127^{* * *}$ & $-0.00129 * * *$ & 0.0275 & -0.000295 \\
\hline & $(0.0343)$ & $(0.000345)$ & $(0.0478)$ & $(0.000483)$ \\
\hline$\%$ change (relative to female baseline) & $7 \% * * *$ & $0 \% * * *$ & $2 \%$ & $-0.02 \%$ \\
\hline \multirow[t]{2}{*}{$=1$ if Agree that it's acceptable to beat ones wife if she refuses sex } & $0.101 * * *$ & $-0.00102^{* * *}$ & $0.0661^{*}$ & $-0.000674^{*}$ \\
\hline & $(0.0247)$ & $(0.000250)$ & (0.0341) & $(0.000347)$ \\
\hline$\%$ change (relative to female baseline) & $6 \% * * *$ & $-0.06 \% * * *$ & $4 \% *$ & $-0.04 \% *$ \\
\hline \multirow[t]{2}{*}{$=1$ if Agree that it's acceptable to beat ones wife if she burns food } & $0.0570 * *$ & $-0.000580 * *$ & 0.0166 & -0.000169 \\
\hline & $(0.0219)$ & $(0.000223)$ & $(0.0307)$ & $(0.000312)$ \\
\hline$\%$ change (relative to female baseline) & $3 \% * *$ & $-0.03 \% * *$ & $0.89 \%$ & $-9.02296 \mathrm{E}-05$ \\
\hline \multirow[t]{2}{*}{$=1$ if Agree that it's acceptable to beat ones wife if she annoying } & 0.0325 & -0.000333 & 0.0495 & -0.000496 \\
\hline & (0.0259) & $(0.000262)$ & $(0.0460)$ & $(0.000463)$ \\
\hline$\%$ change (relative to female baseline) & $1.75 \%$ & $-0.02 \%$ & $2.67 \%$ & $-0.03 \%$ \\
\hline \multirow[t]{2}{*}{$=1$ if Agree that it's acceptable to beat ones wife for any reason } & 0.0265 & -0.000265 & 0.0334 & -0.000346 \\
\hline & $(0.0232)$ & $(0.000236)$ & $(0.0355)$ & $(0.000361)$ \\
\hline \% change (relative to female baseline) & $1.41 \%$ & $-0.01 \%$ & $1.77 \%$ & $-0.02 \%$ \\
\hline \multirow{2}{*}{$\begin{array}{l}=1 \text { if Agree that it's acceptable to beat ones wife that it's never ok to beat } \\
\text { wife }\end{array}$} & $-0.0848 * *$ & $0.000863 * *$ & -0.0185 & 0.000182 \\
\hline & $(0.0373)$ & $(0.000377)$ & $(0.0566)$ & $(0.000571)$ \\
\hline$\%$ change (relative to female baseline) & $-5.40 \% * *$ & $0.05 \% * *$ & $-1.18 \%$ & $0.01 \%$ \\
\hline
\end{tabular}

Notes: Robust standard errors clustered at the village level are reported in parentheses. Results that are significant at the $0.05(0.10,0.01)$ level are marked with $a^{* *}(*, * *)$. Each row presents the results from a separate regression with the dependent variables listed in each row. Percent changes in panel $B$ are based on comparison to females in the control group prior to treatment. Participants refer to individuals randomly selected to attend the program that consisted of a set of 6 discussion sessions. Non-Participants refer to individuals who did not attend the program. 

Table 6. Estimated Effect of Discussion Sessions on Violence Levels (Burundi)

\begin{tabular}{|c|c|c|c|c|}
\hline & \multicolumn{2}{|c|}{ Non-Participants } & \multicolumn{2}{|c|}{ Participants } \\
\hline & females & males & females & males \\
\hline \multicolumn{5}{|l|}{ Panel A: Baseline } \\
\hline \multirow[t]{2}{*}{ Physically Hurt } & $1.185^{* * *}$ & 0.011 & 0.015 & 0.000 \\
\hline & $(0.0320)$ & $(0.0185)$ & $(0.0359)$ & $(0.000363)$ \\
\hline \multirow[t]{2}{*}{ Insult } & $1.821 * * *$ & $-0.217 * * *$ & -0.044 & 0.000 \\
\hline & $(0.0731)$ & $(0.0415)$ & $(0.0656)$ & $(0.000663)$ \\
\hline \multirow[t]{2}{*}{ Threaten } & $1.350 * * *$ & $-0.131 * * *$ & -0.069 & 0.000676 \\
\hline & $(0.0575)$ & $(0.0392)$ & $(0.0504)$ & $(0.0392)$ \\
\hline \multirow[t]{2}{*}{ Scream } & $2.144^{* * *}$ & -0.131 & -0.082 & 0.001 \\
\hline & $(0.0759)$ & $(0.0514)$ & $(0.0734)$ & $(0.000740)$ \\
\hline \multirow{2}{*}{ tothit $>5$} & $0.304 * * *$ & $-0.0685 * * *$ & -0.0424 & 0.000424 \\
\hline & $(0.0336)$ & $(0.0180)$ & $(0.0341)$ & $(0.000342)$ \\
\hline \multicolumn{5}{|l|}{ Panel B: Post Program } \\
\hline \multirow[t]{2}{*}{ Physically Hurt } & $-0.09 * * *$ & $0.001 * * *$ & -0.0385 & 0.000399 \\
\hline & $(0.0232)$ & $(0.000233)$ & $(0.0356)$ & $(0.000360)$ \\
\hline$\%$ change (relative to female baseline) & $-0.08 * * *$ & $0.001 * * *$ & -0.032 & 0.000 \\
\hline \multirow[t]{2}{*}{ Insult } & $-0.15 * * *$ & $0.00152 * *$ & -0.0573 & -0.00122 \\
\hline & $(0.000663)$ & $(0.000675)$ & $(0.0912)$ & $(0.00148)$ \\
\hline$\%$ change (relative to female baseline) & $-0.08 * * *$ & $0.001 * *$ & -0.031 & 0.001 \\
\hline \multirow{2}{*}{ Threaten } & -0.03 & 0.000 & 0.005 & -0.0000432 \\
\hline & $(0.0437)$ & $(0.000446)$ & $(0.0504)$ & $(0.000541)$ \\
\hline$\%$ change (relative to female baseline) & -0.02 & 0.000 & -0.0685 & 0.000 \\
\hline \multirow[t]{2}{*}{ Scream } & $-0.22 * * *$ & $0.002 * * *$ & -0.019 & 0.000191 \\
\hline & $(0.0743)$ & $(0.000754)$ & $(0.0907)$ & $(0.000918)$ \\
\hline$\%$ change (relative to female baseline) & $-0.10 * * *$ & $0.001 * * *$ & -0.009 & $8.90858 \mathrm{E}-05$ \\
\hline \multirow[t]{2}{*}{ tothit $>5$} & -0.08 & $0.000836^{* *}$ & 0.00999 & -0.000273 \\
\hline & $(0.0300)$ & $(0.000302)$ & $(0.0450)$ & $(0.000454)$ \\
\hline$\%$ change (relative to female baseline) & $-0.28 * * *$ & $0.003^{* *}$ & 0.033 & -0.001 \\
\hline
\end{tabular}


Notes: Robust standard errors clustered at the village level are reported in parentheses. Results that are significant at the $0.05(0.10,0.01)$ level are marked with $a^{* *}(*, * * *)$. Each row presents the results from a separate regression with the dependent variables listed in each row. Percent changes in panel B are based on comparison to females in the control group prior to treatment. Participants refer to individuals randomly selected to attend the program that consisted of a set of 6 discussion sessions. Non-Participants refer to individuals who did not attend the program 
Table 7. Comparison of Baseline Levels of Decision Making, Attitudes and Violence Between Control and Program Participation Groups (South Africa)

\begin{tabular}{|c|c|c|c|c|c|c|c|c|c|}
\hline & \multicolumn{3}{|c|}{ Non-Participants } & \multicolumn{3}{|c|}{ Participants } & \multicolumn{3}{|c|}{ Summary } \\
\hline & $\mathrm{N}$ & Mean & SD & $\mathrm{N}$ & Mean & SD & $\mathrm{t}$ & Diff & \%Chng \\
\hline \multicolumn{10}{|l|}{ Panel A: Violence } \\
\hline Total Violence (Push, Hit, Forcesex) & 178 & 0.163 & 0.593 & 193 & 0.187 & 0.609 & -0.378 & -0.024 & 1.145 \\
\hline Insulted by partner - Past Year Experience & 178 & 0.899 & 0.302 & 193 & 0.87 & 0.337 & 0.856 & 0.028 & 0.968 \\
\hline Pushed by partner - Past Year Experience & 178 & 0.067 & 0.251 & 193 & 0.083 & 0.276 & -0.565 & -0.015 & 1.23 \\
\hline Partner hit w\fist - Past Year Experience & 178 & 0.051 & 0.22 & 193 & 0.067 & 0.251 & -0.687 & -0.017 & 1.332 \\
\hline \multicolumn{10}{|l|}{ Panel B: Decision Making } \\
\hline Large purchases self, ask partner & 178 & 0.225 & 0.419 & 190 & 0.237 & 0.426 & -0.275 & -0.012 & 1.054 \\
\hline Small purchases household, ask partner & 178 & 0.781 & 0.415 & 190 & 0.847 & 0.361 & -1.636 & -0.066 & 1.085 \\
\hline Medium purchases household, ask partner & 176 & 0.426 & 0.496 & 189 & 0.36 & 0.481 & 1.296 & 0.066 & 0.844 \\
\hline Large Purchases household, ask partner & 178 & 0.152 & 0.36 & 190 & 0.105 & 0.308 & 1.326 & 0.046 & 0.694 \\
\hline $\begin{array}{l}\text { Partner encouraged to participate outside } \\
\text { household }\end{array}$ & 178 & 0.506 & 0.501 & 193 & 0.477 & 0.501 & 0.556 & 0.029 & 0.943 \\
\hline Partner asks for advice & 178 & 0.416 & 0.494 & 193 & 0.451 & 0.499 & -0.679 & -0.035 & 1.084 \\
\hline Partner keeps from friends & 178 & 0.888 & 0.317 & 193 & 0.876 & 0.331 & 0.357 & 0.012 & 0.986 \\
\hline Partner restricts contact $w \backslash$ family & 178 & 0.927 & 0.261 & 193 & 0.922 & 0.268 & 0.17 & 0.005 & 0.995 \\
\hline Partner insists on knowing where she is & 178 & 0.854 & 0.354 & 193 & 0.819 & 0.386 & 0.918 & 0.035 & 0.959 \\
\hline Partner controls access to health care & 178 & 0.899 & 0.302 & 193 & 0.788 & 0.41 & 2.991 & 0.111 & 0.876 \\
\hline Partner boasts g-friends & 178 & 0.938 & 0.241 & 193 & 0.922 & 0.268 & 0.601 & 0.016 & 0.983 \\
\hline Partner threatened eviction & 178 & 0.944 & 0.231 & 193 & 0.891 & 0.312 & 1.855 & 0.053 & 0.944 \\
\hline Spend own money - Ask Partner & 92 & 2.935 & 0.248 & 153 & 2.941 & 0.236 & -0.199 & -0.006 & 1.002 \\
\hline
\end{tabular}

Panel C: Attitudes towards Women and Violence 


\begin{tabular}{|c|c|c|c|c|c|c|c|c|c|}
\hline Women should do all chores & 419 & 1.752 & 0.432 & 424 & 1.663 & 0.473 & 2.852 & 0.089 & 0.949 \\
\hline If paid lobola, wife must obey & 419 & 1.668 & 0.471 & 425 & 1.614 & 0.487 & 1.64 & 0.054 & 0.968 \\
\hline Wife asks condom, disrespectful & 410 & 1.917 & 1.459 & 413 & 1.835 & 0.371 & 1.099 & 0.082 & 0.957 \\
\hline Wife asks condom, sleeps around & 408 & 1.811 & 0.392 & 413 & 1.804 & 0.398 & 0.269 & 0.007 & 0.996 \\
\hline Man has g-friends, must tolerate & 420 & 1.812 & 0.391 & 423 & 1.823 & 0.382 & -0.405 & -0.011 & 1.006 \\
\hline Wife must not divorce & 418 & 1.689 & 0.463 & 422 & 1.690 & 0.463 & -0.018 & -0.001 & 1.00 \\
\hline Ok to refuse sex if not want & 416 & 1.538 & 0.499 & 423 & 1.522 & 0.5 & 0.464 & 0.016 & 0.99 \\
\hline Ok to refuse sex if worried about aids & 416 & 1.498 & 0.501 & 423 & 1.428 & 0.495 & 2.027 & 0.07 & 0.953 \\
\hline
\end{tabular}

Notes: Outcome measures based on survey data collected by Intervention with Microfinance for Gender Equity (IMAGE) in South Africa, a cooperative study between the London School of Hygiene and Tropical Medicine (LSHTM), Wits University in Johannesburg, and the microfinance NGO Small Enterprise Foundation (SEF). Results presented in Kim et al (2009). Estimates based on authors' own calculations of the data from Kim et al (2009). Participants refer to individuals randomly selected to attend program consisting of a set of 10-discussion sessions. Non-Participants refer to individuals who did not attend the program. Comparison columns report mean difference between participant and non-participant groups. Also reported are the t-statistics testing if this difference is distinguishable from zero. 
Table 8. Comparison of Sociodemographic Characteristics Between Control and Program Participation Groups (South Africa)

\begin{tabular}{|c|c|c|c|c|c|c|c|c|c|}
\hline & \multicolumn{3}{|c|}{ Non-Participants } & \multicolumn{3}{|c|}{ Participants } & \multicolumn{3}{|c|}{ Comparison } \\
\hline & $\mathrm{N}$ & Mean & SD & $\mathrm{N}$ & Mean & SD & $\mathrm{t}$ & Diff & \%Chng \\
\hline Age & 420 & 42.519 & 12.594 & 426 & 42.077 & 10.904 & 0.545 & 0.442 & 0.99 \\
\hline Marital Status & 420 & 2.15 & 1.09 & 426 & 2.277 & 1.049 & -1.727 & -0.127 & 1.059 \\
\hline Parity & 420 & 4.417 & 2.885 & 425 & 5.009 & 2.955 & -2.95 & -0.593 & 1.134 \\
\hline Connectedness & 426 & 2.178 & 1.263 & 428 & 2.874 & 1.383 & -7.671 & -0.695 & 1.319 \\
\hline Maximum Schooling & 425 & 1.386 & 0.572 & 426 & 1.458 & 0.632 & -1.739 & -0.072 & 1.052 \\
\hline Livestock Value & 413 & $1,057.56$ & $3,139.42$ & 422 & $1,664.92$ & $5,978.12$ & -1.843 & -607.358 & 1.574 \\
\hline Type of Toilet & 421 & 2.268 & 0.485 & 425 & 2.191 & 0.405 & 2.533 & 0.078 & 0.966 \\
\hline Access to Electricity & 422 & 1.218 & 0.413 & 425 & 1.195 & 0.397 & 0.816 & 0.023 & 0.981 \\
\hline Dwelling Walls Material & 422 & 4.265 & 1.241 & 425 & 4.393 & 1.306 & -1.457 & -0.128 & 1.03 \\
\hline Access to Water & 416 & 2.565 & 1.162 & 425 & 3.226 & 1.483 & -7.204 & -0.661 & 1.258 \\
\hline
\end{tabular}

Notes: Outcome measures based on survey data collected by Intervention with Microfinance for Gender Equity (IMAGE) in South Africa, a cooperative study between the London School of Hygiene and Tropical Medicine (LSHTM), Wits University in Johannesburg, and the microfinance NGO Small Enterprise Foundation (SEF). Results presented in Kim et al (2009). Estimates based on authors' own calculations of the data from Kim et al (2009) . Participants refer to individuals randomly selected to attend program consisting of a set of 10-discussion sessions. Non-Participants refer to individuals who did not attend the program. Comparison columns report mean difference between participant and non-participant groups. Also reported are the t-statistics testing if this difference is distinguishable from zero. 
Table 9. Estimated Effect of Discussion Sessions on Decision Making and Dispute Resolution Outcomes (South Africa)

\begin{tabular}{|c|c|c|c|c|}
\hline \multirow[b]{2}{*}{ Does not ask husband's permission for: } & \multicolumn{2}{|c|}{ Baseline } & \multicolumn{2}{|c|}{ Post-Program } \\
\hline & Non-Participants & Participants & Non-Participants & Participants \\
\hline \multirow[t]{2}{*}{ Small purchases for herself } & $0.359 * * *$ & -0.067 & $0.200^{*}$ & 0.174 \\
\hline & $(0.0626)$ & $(0.0791)$ & $(0.0856)$ & $(0.103)$ \\
\hline$\%$ change relative to non-participant baseline & & $-19 \%$ & $56 \%$ & $48 \%$ \\
\hline Large purchases for own self, does not ask for & $0.228 * * *$ & -0.00302 & 0.143 & 0.0945 \\
\hline husband's permission & $(0.0503)$ & $(0.09)$ & $(0.0924)$ & $(0.156)$ \\
\hline$\%$ change relative to non-participant baseline & & $-1 \%$ & $63 \%$ & $41 \%$ \\
\hline Small purchases for the hh, does not ask for husband's & $0.672^{* * *}$ & 0.0495 & 0.123 & 0.00542 \\
\hline Permission & $(0.068)$ & $(0.0459)$ & $(0.0688)$ & $(0.0807)$ \\
\hline$\%$ change relative to non-participant baseline & & $7.40 \%$ & $18.30 \%$ & $0.80 \%$ \\
\hline Medium purchases for the hh, does not ask for & $0.351 * * *$ & -0.0921 & $0.240 * *$ & $0.233^{* *}$ \\
\hline husband's permission & $(0.0522)$ & $(0.0615)$ & $(0.0774)$ & $(0.0928)$ \\
\hline$\%$ change relative to non-participant baseline & & $-26.24 \%$ & $68.38 \% * *$ & $66.38 \% * *$ \\
\hline \multirow[t]{2}{*}{ Large purchases for the hh } & $0.228 * * *$ & -0.0518 & 0.0837 & 0.171 \\
\hline & $(0.0503)$ & $(0.0781)$ & $(0.0891)$ & $(0.13)$ \\
\hline$\%$ change relative to non-participant baseline & & $-23 \%$ & $37 \%$ & $75 \%$ \\
\hline \multirow[t]{2}{*}{ Taking children to hospital, } & $0.520 * * *$ & -0.0785 & 0.0618 & 0.199 \\
\hline & $(0.118)$ & $(0.113)$ & $(0.171)$ & $(0.195)$ \\
\hline$\%$ change relative to non-participant baseline & & $-15.10 \%$ & $11.90 \%$ & $38.30 \%$ \\
\hline \multirow[t]{2}{*}{ Visit Family of Birth } & $0.352^{* * *}$ & -0.0986 & -0.0776 & 0.314 \\
\hline & (0.097) & $(0.108)$ & $(0.136)$ & $(0.177)$ \\
\hline
\end{tabular}




\begin{tabular}{|c|c|c|c|c|}
\hline$\%$ change relative to non-participant baseline & & $-28 \%$ & $-22 \%$ & $89 \%$ \\
\hline \multirow[t]{2}{*}{ Visit Friends } & $0.491^{* * *}$ & -0.0317 & 0.16 & 0.124 \\
\hline & $(0.0854)$ & $(0.0869)$ & $(0.118)$ & $(0.143)$ \\
\hline$\%$ change relative to non-participant baseline & & $-6.46 \%$ & $32.59 \%$ & $25.25 \%$ \\
\hline Visits Family and Friends outside the & $0.260 * * *$ & -0.00703 & 0.0165 & 0.169 \\
\hline husband's permission & $(0.0598)$ & $(0.0814)$ & $(0.0874)$ & (0.143) \\
\hline$\%$ change relative to non-participant baseline & & $-2.70 \%$ & $6.30 \%$ & $65.00 \%$ \\
\hline
\end{tabular}

Notes: Robust standard errors clustered at the village level are reported in parentheses. Results that are significant at the $0.05(0.10,0.01)$ level are marked with $a^{* *}(*, * *)$. Each row presents the results from a separate regression with the dependent variables listed in each row.

Percent changes in panel B are based on comparison to females in the control group prior to treatment. Outcome measures based on survey data collected by Intervention with Microfinance for Gender Equity (IMAGE) in South Africa, a cooperative study between the London School of Hygiene and Tropical Medicine (LSHTM), Wits University in Johannesburg, and the microfinance NGO Small Enterprise Foundation (SEF). Results presented in Kim et al (2009). Estimates based on authors' own calculations of the data from Kim et al (2009). Participants refer to individuals randomly selected to attend 10 -series discussion group series. Non-Participants refer to individuals not selected to attend the program. 
Table 10. Estimated Effect of Discussion Sessions on Gender Norms and Violence (South Africa)

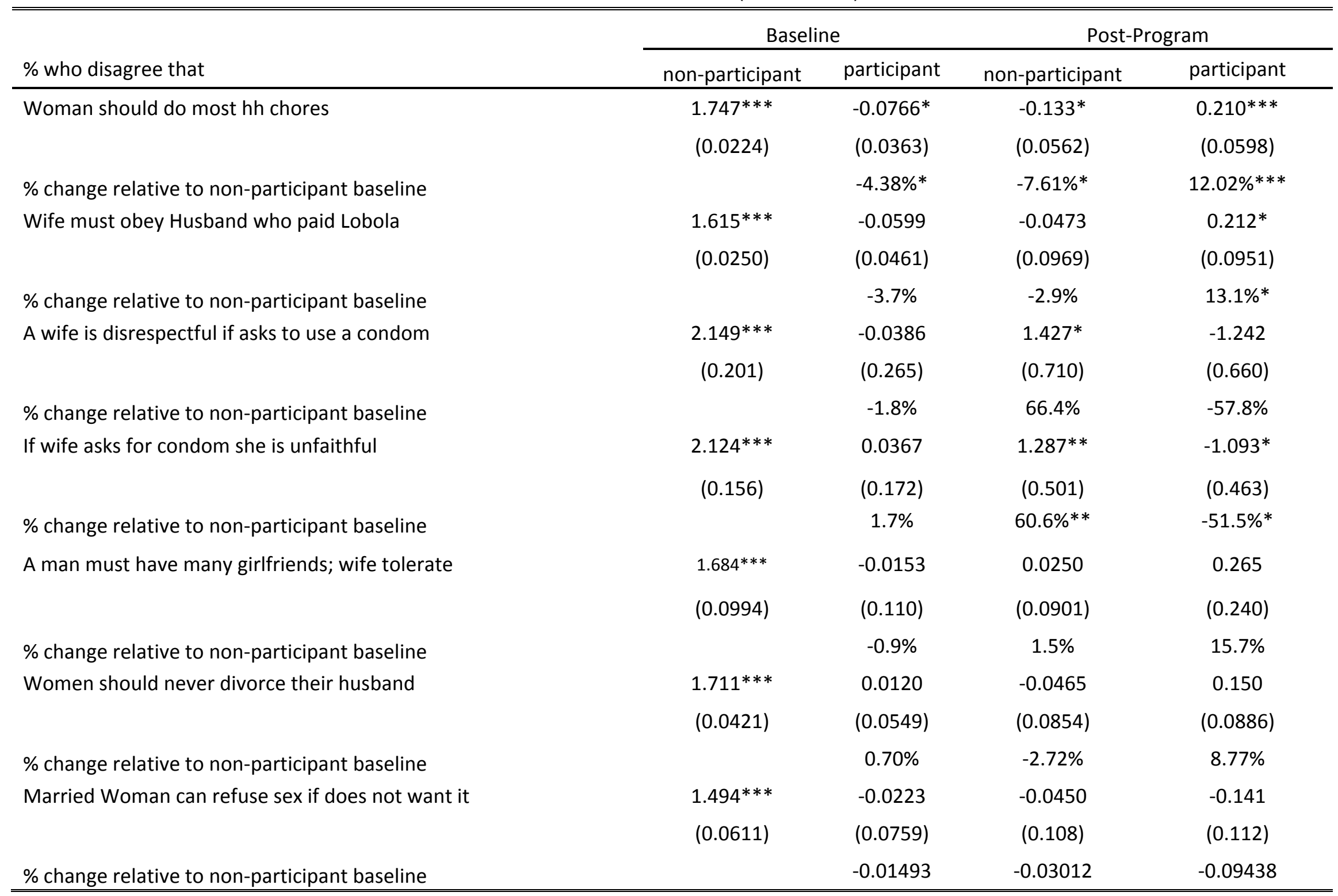




\begin{tabular}{|c|c|c|c|c|}
\hline \multirow[t]{2}{*}{ Married woman can refuse sex if husband will not wear a condom } & $1.596 * * *$ & -0.0199 & $0.874 *$ & $-1.003 * *$ \\
\hline & $(0.132)$ & $(0.145)$ & $(0.453)$ & $(0.419)$ \\
\hline$\%$ change relative to non-participant baseline & & $-1.2 \%$ & $54.8 \% *$ & $-62.8 \% * *$ \\
\hline If she is angry because he has other g-friends, & $1.395^{* * *}$ & -0.0579 & 0.146 & -0.311 \\
\hline married woman can refuse sex & $(0.106)$ & $(0.0537)$ & $(0.202)$ & $(0.192)$ \\
\hline$\%$ change relative to non-participant baseline & & $-4 \%$ & $10 \%$ & $-22 \%$ \\
\hline \multirow[t]{2}{*}{ She worries he might have AIDS, married woman can refuse sex } & $1.282 * * *$ & -0.0491 & 1.017 & -1.172 \\
\hline & $(0.224)$ & $(0.255)$ & $(0.799)$ & $(0.739)$ \\
\hline$\%$ change relative to non-participant baseline & & $-4 \%$ & $79 \%$ & $-91 \%$ \\
\hline \multirow[t]{2}{*}{ Ok to beat wife if she refuses to have sex } & $1.830 * * *$ & $0.0368^{*}$ & -0.00277 & 0.000886 \\
\hline & $(0.00972)$ & $(0.0184)$ & $(0.00192)$ & $(0.00183)$ \\
\hline$\%$ change relative to non-participant baseline & & $2.0 \% *$ & $-0.2 \%$ & $0.0 \%$ \\
\hline \multirow[t]{2}{*}{ Ok to beat wife if she asks to use a condom } & $2.634^{* * *}$ & -0.477 & 0.00632 & -0.00740 \\
\hline & $(0.195)$ & $(0.291)$ & $(0.00654)$ & $(0.00934)$ \\
\hline$\%$ change relative to non-participant baseline & & $-18.1 \%$ & $0.2 \%$ & $-0.3 \%$ \\
\hline \multirow[t]{2}{*}{ Ok to beat wife if she is unfaithful } & $1.724 * * *$ & 0.0150 & -0.00257 & 0.00120 \\
\hline & $(0.0367)$ & $(0.0284)$ & $(0.00280)$ & $(0.00282)$ \\
\hline$\%$ change relative to non-participant baseline & & $0.87 \%$ & $-0.15 \%$ & $0.07 \%$ \\
\hline \multirow[t]{2}{*}{ Ok to beat wife if she disagrees in public } & $1.924^{* * *}$ & -0.502 & 0.00536 & -0.00184 \\
\hline & $(0.181)$ & $(0.354)$ & $(0.00658)$ & $(0.00434)$ \\
\hline$\%$ change relative to non-participant baseline & & $-26.09 \%$ & $0.28 \%$ & $-0.10 \%$ \\
\hline
\end{tabular}

Notes: Robust standard errors clustered at the village level are reported in parentheses. Results that are significant at the 0.05 $(0.10,0.01)$ level are marked with $a^{* *}(*, * * *)$. Each row presents the results from a separate regression with the dependent variables listed in each row. Percent changes in panel $B$ are based on comparison to females in the control group prior to treatment. Outcome measures based on survey data collected by Intervention with Microfinance for Gender Equity (IMAGE) in South Africa, a cooperative study between the London School of Hygiene and Tropical Medicine (LSHTM), Wits University in 
Johannesburg, and the microfinance NGO Small Enterprise Foundation (SEF). Results presented in Kim et al (2009). Estimates based on authors' own calculation of the data from Kim et al (2009). Participants refer to individuals randomly selected to attend program consisting of a set of 10 -discussion sessions. Non-Participants refer to individuals who did not attend the program. 
Table 11. Estimated Effect of Discussion Sessions on Violence and Consumption Levels (South Africa)

\begin{tabular}{|c|c|c|c|c|}
\hline & \multicolumn{2}{|c|}{ Baseline } & \multicolumn{2}{|c|}{ Post-Program } \\
\hline & non-participant & participant & non-participant & participant \\
\hline \multirow[t]{2}{*}{ Insult } & $0.882 * * *$ & -0.0176 & 0.0239 & $0.0309 *$ \\
\hline & $(0.0237)$ & $(0.0104)$ & $(0.0140)$ & $(0.0137)$ \\
\hline$\%$ change relative to non-participant baseline & & $-2 \%$ & $2.71 \%$ & $3.50 \% *$ \\
\hline \multirow[t]{2}{*}{ Push } & $0.0915^{* * *}$ & 0.0112 & 0.00612 & $-0.0466 * *$ \\
\hline & $(0.00684)$ & $(0.00801)$ & $(0.0117)$ & $(0.0168)$ \\
\hline$\%$ change relative to non-participant baseline & & $12.2 \%$ & $6.7 \%$ & $-51 \% * *$ \\
\hline \multirow[t]{2}{*}{ Has been hit with a fist by partner } & $0.0782 * * *$ & $0.0129 *$ & 0.0157 & $-0.0371 * *$ \\
\hline & $(0.00532)$ & $(0.00550)$ & $(0.00950)$ & $(0.0121)$ \\
\hline$\%$ change relative to non-participant baseline & & $16.50 \% *$ & $20 \%$ & $-47 \% * *$ \\
\hline \multirow[t]{2}{*}{ Has had Forced Sex w Partner } & $0.0720 * * *$ & -0.00237 & $0.0195^{*}$ & -0.0223 \\
\hline & $(0.00799)$ & $(0.00435)$ & $(0.00833)$ & $(0.0164)$ \\
\hline$\%$ change relative to non-participant baseline & & $-3 \%$ & $27.08 \% *$ & $-31 \%$ \\
\hline \multirow[t]{2}{*}{ Total Violence } & $0.231 * * *$ & 0.0204 & $0.0337^{*}$ & $-0.0844 * * *$ \\
\hline & $(0.0189)$ & $(0.0147)$ & $(0.0161)$ & $(0.0239)$ \\
\hline$\%$ change relative to non-participant baseline & & $9 \%$ & $14.59 \% *$ & $-37 \% * * *$ \\
\hline
\end{tabular}

Notes: Robust standard errors clustered at the village level are reported in parentheses. Results that are significant at the 0.05 $(0.10,0.01)$ level are marked with a ${ }^{* *}(*, * * *)$. Each row presents the results from a separate regression with the dependent variables listed in each row. Percent changes in panel B are based on comparison to females in the control group prior to treatment. Outcome measures based on survey data collected by Intervention with Microfinance for Gender Equity (IMAGE) in South Africa, a cooperation between the London School of Hygiene and Tropical Medicine (LSHTM), Wits University in Johannesburg, and the microfinance NGO Small Enterprise Foundation (SEF). Results presented in Kim et al (2009). Estimates based on author's own calculations. Participants refer to individuals randomly selected to attend 10-series discussion group series. Non-Participants refer to individuals not selected to attend the program. 
